\title{
Application of Next Generation Sequencing in Laboratory Medicine
}

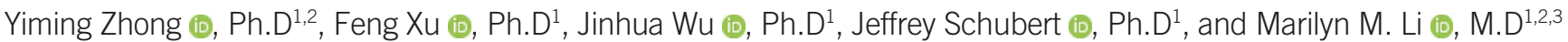 \\ ${ }^{1}$ Department of Pathology \& Laboratory Medicine, Children's Hospital of Philadelphia, Philadelphia, PA, USA; ${ }^{2}$ Department of Pathology and Laboratory \\ Medicine, Perelman School of Medicine, University of Pennsylvania, Philadelphia, PA, USA; ${ }^{3}$ Department of Pediatrics, Children's Hospital of Philadelphia, \\ Philadelphia, PA, USA
}

The rapid development of next-generation sequencing (NGS) technology, including advances in sequencing chemistry, sequencing technologies, bioinformatics, and data interpretation, has facilitated its wide clinical application in precision medicine. This review describes current sequencing technologies, including short- and long-read sequencing technologies, and highlights the clinical application of NGS in inherited diseases, oncology, and infectious diseases. We review NGS approaches and clinical diagnosis for constitutional disorders; summarize the application of U.S. Food and Drug Administration-approved NGS panels, cancer biomarkers, minimal residual disease, and liquid biopsy in clinical oncology; and consider epidemiological surveillance, identification of pathogens, and the importance of host microbiome in infectious diseases. Finally, we discuss the challenges and future perspectives of clinical NGS tests.

Key Words: Next-generation sequencing, Oncology, Constitutional disorders, Infectious diseases

\author{
Received: February 27, 2020 \\ Revision received: March 24, 2020 \\ Accepted: August 7, 2020
}

Corresponding author: Yiming Zhong, Ph.D. Department of Pathology \& Laboratory

Medicine Children's Hospital of Philadelphia, Perelman School of Medicine at University of Pennsylvania 3615 Civic Center Blvd, 716H ARC Philadelphia, PA 19104, USA

Tel: $+1-215-5900488$

Fax: +1-215-5902156

E-mail: zhongy1@email.chop.edu

\section{INTRODUCTION}

Next-generation sequencing (NGS), also known as massively parallel sequencing or high-throughput sequencing, is a technology allowing simultaneous sequencing of millions of DNA or RNA sequences. The advantages of NGS compared with traditional sequencing methods include higher throughput with sample multiplexing, higher sensitivity in detecting low-frequency variants, faster turnaround time for high sample volumes, and lower cost. NGS represents a true sequencing technology revolution after Sanger sequencing [1]. Sequencing the first human genome using Sanger sequencing required many years and billions of dollars; however, with the emergence of NGS, a complete human genome can now be sequenced within a few days for less than $\$ 1,000$ [2]. NGS has a wide spectrum of applications in laboratory medicine and has become an integrated part of precision medicine. The technology has been widely used in diagnosis, prognosis, and therapy selection for constitutional disorders, oncology, and infectious diseases [3-5]. Concurrently, an increasing amount of well curated clinical, genetic, and genomic data is being generated by NGS, further driving the development of precision medicine [6]. The U.S. Food and Drug Administration (FDA) recently released a set of guidelines for the design, development, and validation of NGS tests and approved several NGS-based tests and targeted therapies [7-9]. In addition, the Centers for Medicare \& Medicaid Services (CMS) has been actively monitoring the rapid innovation of NGS tests and working to ensure coverage of NGS-based tests. All these advances have accelerated the clinical application of NGS in laboratory medicine. This review highlights recent 
developments in NGS technologies and their clinical application in diagnosis, prognosis, and therapeutics of inherited diseases, cancers, and infectious diseases.

\section{NGS TECHNOLOGIES}

Historically, DNA sequencing technologies have played important roles in molecular biology and clinical fields [10-13]. The first-generation platform, Sanger sequencing, was developed by Fred Sanger in 1977 and has been used for decades in research and clinical genetics [14-16]. Three decades later, NGS technologies have evolved rapidly, leading to the invention of second and third generation sequencing technologies. Sequencing turnaround time and cost have been dramatically reduced since 2001 when the first draft map of the human genome was accomplished [17-26]. In this section, we discuss the commonly used next generation sequencers and their strengths and challenges.

\section{Second generation sequencing technologies}

Various second-generation sequencing technologies have been developed by different commercial companies. Overall, the workflows of the different sequencing technologies include three steps: (1) template preparation including nucleic acid extraction; (2) library preparation including clonal amplification; and (3) sequencing and alignment of short reads.

Roche 454 sequencing (Roche, Basel, Switzerland), launched in 2005, was the first commercially available massive parallel sequencing platform. Roche 454 sequencing uses pyrosequencing technology, which captures pyrophosphate (PPi) release and uses it as an indicator of specific base incorporation. Fragmented DNA is bound to beads with ligated adaptors followed by fragment amplification via emulsion PCR within an emulsion droplet [27]. The beads containing multiple copies of the same DNA template are then loaded into PicoTiterPlate (PTP) wells. Each nucleotide is sequentially flowed into the PTP wells. Each time a nucleotide is incorporated during DNA synthesis, it releases pyrophosphate, which is converted to ATP. In the presence of ATP, luciferase coverts luciferin to oxyluciferin to generate light, which is then detected and captured by a coupled-charge device (CCD) camera [28-30]. Sequencing accuracy is dependent on the reading of the light signals. A misread or missing signal, especially in homopolymer sequencing, could result in base errors and insertions or deletions. The Roche 454 sequencer genome sequencing (GS)-FLX, launched in 2008, could generate approximately $700 \mathrm{Mb}$ of sequence data per run with read lengths up to 1,000 bases in approximately 20 hours [31]. Roche 454 was phased out of the NGS field in 2016 because of its much higher cost compared with other high throughput NGS sequencers such as the Ion Torrent (Thermo Fisher, Waltham, MA, USA) and Illumina (San Diego, CA, USA) systems.

Unlike other technologies using fluorescence or chemiluminescence, Ion Torrent uses sequencing via hydrogen ion detection technology, which detects the release of protons while nucleotides are being incorporated into the strands during synthesis. The fragmented DNA is attached to 3-micron diameter beads with specific adapter sequences. Clonal amplification happens via emulsion PCR on the beads [27], and the beads are then loaded into microwells. The change in $\mathrm{pH}$ due to proton release, generated by the incorporation of each base during synthesis, is detected by the sensing layer of the microwell, which translates the chemical signal into a digital one [32]. The first lon Torrent Personal Genome Machine (PGM) sequencer was released in 2010. PGM has an output of up to 2 GB per run and fast run time (2-7 hours), which is suitable for targeted sequencing or smaller/genomes [32, 33]. In 2012, Ion Torrent released the Proton sequencer, which provides a higher throughput at the same speed and is capable of sequencing both exomes and human genomes $[34,35]$. Compared with the PGM and Proton sequencers, the Ion GeneStudio S5 series sequencers, launched in 2015, changed the instrument cartridges and reagents resulting in easier preparation and shorter run time [36]. Rather than relying on the laser scanners/CCD cameras used in other sequencing technologies, the Ion Torrent platform is more rapid, direct, and less expensive. However, lon sequencers do have sequencing error issues such as artifact insertions/deletions (indels) associated with homopolymeric stretches and repeats [35].

Illumina platforms are currently widely used in the NGS field [37-43]. Illumina developed a bridge PCR approach for clonal amplification and sequencing by reversible termination technology. Both ends of the fragmented DNA anneal to two fixed adapters, which are immobilized to the solid surface of the flowcell, followed by bridge amplification to form clusters that contain clonal DNA fragments. Each reversible terminator (RT) nucleotide (ddATP, ddGTP, ddCTP, ddTTP) is protected at the 3'$\mathrm{OH}$ group and contains a cleavable fluorescent dye. Modified RT nucleotides are incorporated into the growing DNA chains during synthesis and release fluorescent signals, which are captured and recorded using a CCD camera. This technology significantly reduces the homopolymer sequencing error by incorporating a single base at a time, as the addition of another base requires that a terminator first be removed [44, 45]. 
MiSeq (Illumina), one of the most prevalent benchtop sequencers, was launched in 2011. It can produce data ranging from $540 \mathrm{Mb}$ to $15 \mathrm{~Gb}$, which is suitable for sequencing small panels of genes and bacterial genomes [46]. The productionscale sequencer, HiSeq2500 (Illumina), was launched in 2012, with the capacity of sequencing an entire genome in approximately 24 hours. Both platforms use the four-channel sequencing by synthesis (SBS) system, in which each base is detected by individual images. NextSeq 500, launched in 2014, uses two-channel SBS system, which only requires two images to determine all four base calls. This new technology reduces imaging capture time and the number of cycles and hence, decreases sequencing cost and time. The HiSeq X Ten, HiSeq 3000, and HiSeq 4000 systems were launched in 2015; these adopted billions of pre-formatted nanowell grids at fixed locations rather than normal flow-cells, resulting in many folds higher data output compared with MiSeq and HiSeq2500 [45]. NovaSeq, the most powerful sequencer to date, was released in 2017, with the goal of reducing the cost of sequencing a human genome to $\$ 100$. NovaSeq also uses two-channel chemistry, but with larger flow-cells with more nanowells and a faster imaging capture system. It can generate up to $6 \mathrm{~Tb}$ of sequence data and 20 billion reads in approximately two days. NovaSeq allows customers to choose from four different flow cell types with different capacities to meet different sequencing needs. Overall, IIlumina platforms are currently the most popular in both clinical and research settings owing to their high accuracy, relative low cost, and high throughput.

\section{Third generation sequencing technologies}

Although the second-generation sequencing technologies have hugely impacted the NGS field, we still face many challenges such as short sequence reads leading to sequence gaps, alignment issues associated with repetitive regions or pseudogenes, and PCR artifacts. To overcome these limitations, third generation sequencing technologies, single molecule sequencingbased technologies, were developed [47-49]. Pacific Biosciences (Menlo Park, CA, USA) (Pac Bio) single molecule realtime (SMRT) and Oxford Nanopore sequencing technologies (Oxford Nanopore Technologies, Oxford, UK) are representatives of this generation [50].

PacBio SMRT technology does not require amplification and offers much longer reads than second generation sequencing technologies. The library preparation is similar to that of secondgeneration sequencing technologies, except that the adapters used in library preparation have a hairpin structure to ensure that the double-stranded DNA fragments become circular after ligation to form the SMRTbell template. The bases are sequenced by synthesis in real time on a chip containing millions of zero mode waveguides (ZMWs), which are nanowells several nanometers in diameter and approximately $100 \mathrm{~nm}$ in depth. The template molecule and DNA polymerase are immobilized at the bottom of each ZMW. During the sequencing reactions, the complementary strand of the template is elongated by DNA polymerase with fluorescently labeled deoxyribonucleotide triphosphates. The CCD camera inside of the machine captures and records the fluorescent signals in real-time observation [48, 50, 51]. The first PacBio RS (PacBio) was released in 2011, with an average sequencing read length of approximately $1.5 \mathrm{~kb}$ $[49,52]$. Two years later, RS II was released, with an average read length of approximately $20 \mathrm{~kb}$ [48, 53]. In 2015, PacBio launched a new SMRT system, Sequel, with larger cells and an increased number of ZMWs, which produces an average read length between 8-12 kb [53]. The upgraded Sequel II system can currently generate eight-fold the sequence data with $50 \%$ of the reads $\geq 50 \mathrm{~kb}$. PacBio technology has a few advantages compared with the second-generation sequencing technologies, including much shorter sample preparation time (4-6 hours) and sequencing run time (within a day/run), much longer sequencing reads (average 10-15 kb), and reduced GC bias and sequencing errors due to PCR amplification. However, this technology has a few inherent drawbacks including a relatively high error rate (10-15\%). Most errors are due to indels, and a small portion is caused by miscalls. This error rate can be reduced by multiple sequencing runs $[53,54]$.

The other representative third-generation sequencing technology is Oxford Nanopore; this novel technology uses nanopores, tiny biopores with a nanoscale diameter, and measures current changes, instead of SBS or fluorescence detection approaches. Any particle passing through the pore interrupts the voltage across the channel owing to the nature of the nanopore; each of the four bases leads to a distinctive current change owing to their unique structures. No amplification step or fluorescence labeling is required by this platform, and it does not rely on DNA polymerase like PacBio SMRT. Not only can Nanopore sequence DNA, it can also directly sequence RNA and protein [48]. This technology also has the advantages of short turnaround time and no GC bias. The most apparent disadvantage of the Nanopore technology is a high sequencing error rate of approximately 14\%, and most of the errors are indels.

Overall, the third-generation sequencing technologies provide longer sequence reads, which helps close gaps in current refer- 
Table 1. Summary of commonly used NGS platforms

\begin{tabular}{|c|c|c|c|c|}
\hline Company & Platform(s) & Sequencing mechanism & Read length & Outputs/run time \\
\hline Roche/454 & GS FLX & Pyrosequencing & Up to $1,000 \mathrm{bp}$ & $700 \mathrm{~mol} / / 23 \mathrm{hr}$ \\
\hline Thermo Fisher/lon Torrent & PGM & Detection of hydrogen lon & Up to 400 bp & Up to 4 Gb/day (PGM318) \\
\hline \multirow[t]{4}{*}{ Illumina } & MiSeq & Reversible terminator & Up to 300 bp & Up to $15 \mathrm{~Gb} / 56 \mathrm{hr}$ \\
\hline & HiSeq 2500 & & Can be up to $250 \mathrm{bp}$ & 60 hrs for up to $300 \mathrm{~Gb}$ (rapid mode) \\
\hline & HiSeq 4000 & & Can be up to 150 bp & Up to $1.5 \mathrm{~Tb} / 3$ days \\
\hline & Novate & & $150 \mathrm{bp}$ & Up to $3,000 \mathrm{~Gb} / 44 \mathrm{hr}$ \\
\hline Pacific Biosciences & Sequel & Real-time & $10-15 \mathrm{~kb}$ (average) & 20 Gb/day \\
\hline Oxford Nanopore & MinlON & Real-time & Longest read > $2 \mathrm{Mb}$ & Up to $30 \mathrm{~Gb} / 48 \mathrm{hr}$ \\
\hline
\end{tabular}

Abbreviations: NGS, next-generation sequencing; GS, genome sequencing; PGM, personal genome machine.

ence assemblies generated from short reads and can sequence through extended repetitive regions and characterize structural change in human genomes. However, third generation technologies still have a major issue of high error rate. A hybrid sequencing strategy, combining second- and third- generation NGS technologies, could address some of these issues [55-59]. The background technology, read length, and sequencing capacity of commonly used NGS platforms are summarized in Table 1.

\section{APPLICATION OF NGS IN CONSTITUTIONAL DISORDERS}

The evolution of technologies for the diagnosis of constitutional disorders

NGS is rapidly transforming how research into the genetic determinants of constitutional disorders is performed. The technique is highly efficient, with detailed genetic information produced in a reasonably short time and at a relatively low cost. Several studies have compared the diagnostic yield and cost of NGS with other types of DNA testing. G banding, for example, detects chromosomal aberrations, with a diagnostic yield of approximately $3 \%$ for unexplained constitutional disorders [60]. High-resolution chromosomal microarray analysis (CMA) detects gene copy number variations (CNVs) and has a diagnostic yield of $15-20 \%$ for the same disease categories [60]. NGS whole-exome sequencing (WES) has a diagnostic yield of 25\% for Mendelian disorders [61] and whole-genome sequencing (WGS) has a slightly higher diagnostic yield (27\%) for pediatric and adult genetic diseases [62]. In contrast to WES and WGS, targeted NGS gene panels focus on subsets of genes, ranging from several to hundreds, depending on the focus of the specific diseases. The diagnostic yields of NGS panels vary significantly; for example, congenital glycosylation disorder panel has a reported diagnostic yield of 14.8\% [63], while the prenatal skeletal dysplasia panel has a diagnostic yield of 53\% [64]. In this section, we focus on the process from translational research to clinical diagnosis, molecular diagnosis rate, and patient care, as well as NGS methods in constitutional disorders.

\section{Forward and reverse phenotyping}

Genetic disease studies traditionally progress from phenotype to genotype analysis, the so-called "forward genetics" method [65]. NGS has led to a new process known as reverse phenotyping, in which the genetic marker data are used to drive, or form the basis of, new phenotype definitions [66]. The combination of NGS and segregation analysis may identify a pathogenic variant in a gene that was not known to cause the disease or was previously linked to a different phenotype. In such cases, retrospective clinical interpretation of the patient and their family members can reveal additional characteristics that were unrecognized previously. In a review of over 300 WES studies investigating the causes of rare diseases (between 2010-2012), 178 studies reported a novel disease-associated gene, 51 discussed reverse phenotyping, and 79 reported novel or known variants in a known disease-associated gene [67]. More recent studies have shown that approximately $25 \%$ of reported variants in known disease-associated genes are associated with a phenotype that matched the clinical presentation of the investigated patient [68-71]. These findings highlight the advantages of the "genotype-first" approach in studying rare diseases, especially when phenotypic presentations vary drastically from one patient to another. Thus, NGS provides a powerful molecular tool for establishing a clinical diagnosis even before the disease characteristics are fully revealed.

The number of newly identified disease-associated genes has grown exponentially since the application of NGS technology. 
The identification of a new disease-associated gene or the association of a known gene with new phenotypes is of great significance for patient management including early therapeutic intervention in some cases [72]. The most commonly used approaches for identifying disease-associated genes include: (1) analysis of a group of patients with the same clinical characteristics using WES or WGS and filtering out rare variants in a common gene in all or some members of the group; and (2) proband analysis in conjunction with parents or informative family members and filtering out variants by disease inheritance pattern (autosomal dominant, recessive, X-linked, or de novo) to simplify the process and identify the causal gene.

\section{NGS Strategies for the diagnosis of constitutional diseases} Targeted NGS gene panels

Targeted NGS gene panels are designed for a specific disease or group of diseases, with the ability to maximize coverage, sensitivity, and specificity for the genes of interest. Therefore, targeted NGS gene panels often have higher diagnostic yield than exome sequencing (ES) or genome sequencing (GS). However, when diagnostic uncertainty is high, the diagnostic rate of a targeted NGS gene panel can be lower [73].

Targeted NGS gene panels are often used in the context of a suspected disease or a group of diseases. Diagnostic rates vary across NGS gene panels. For instance, a study using a genetic eye disease panel, including 257 genes, the mitochondrial genome, and previously identified deep intronic pathogenic variants in a cohort of 192 probands, identified a causal variant in 98 of the probands, with a diagnostic rate of 51\% [74]. The diagnostic rate for genetically heterogeneous diseases, such as hereditary hearing loss, could be increased by using a combined approach. A study using tiered ES reported a diagnostic rate of $21 \%$ with Tier 1 testing including Sanger sequencing and targeted deletion analysis of the two most common nonsyndromic hearing loss genes (STRC and GJB2) and two mitochondrial genes (MT-RNR1 and MT-TS1). The diagnostic rate increased to 33\% with Tier 2 testing, including 119 genes and CNV analysis, using array comparative genomic hybridization [75].

The cost of targeted NGS gene panels is variable, but usually significantly lower than that of ES. More expensive panels often incorporate multiple sequencing and copy number analysis techniques to improve the sensitivity of the test.

ES

A study of 500 unselected consecutive patients who received traditional genetic diagnostic evaluations showed that nearly half of the patients remained undiagnosed [76]. Clinical ES targets approximately 22,000 protein-coding genes, increasing the chances of identifying pathogenic variants that may be causal for genetic diseases. ES can also identify risk variants for a specific condition/syndrome that have not been diagnosed in the individual tested; these results are called secondary or incidental depending on whether the gene is deliberately studied. Guidelines for the clinical reporting of these categories of findings have been published [77].

Clinical ES is regularly used for patients with previous negative NGS gene panel tests or complex phenotypes with broad differential diagnoses. This approach has the advantage of evaluating all known disease-associated genes and collecting sequencing data for future reanalysis, as variant classification and new gene discovery advances. When ES is used in patients with a suspected genetic disease without a diagnosis, the molecular diagnostic rate ranges from 24 to 52\% [78-80].

Many studies have aimed to improve diagnostic yield; for example, including the biological parents (trio testing) together with proband testing. In one study, the molecular diagnostic rate increased by $16 \%$ by confirming the de novo status of a variant in the proband or clarifying segregation patterns for recessive diseases by identifying the variant in both unaffected parents [81]. Trio testing with clinical phenotyping strengthens diagnosis confidence. Previous studies have also reported an increased diagnostic rate using re-analysis; a 15\% improvement was achieved by periodical reanalysis of genotype/phenotype data of undiagnosed individuals [82].

\section{GS}

GS is a comprehensive method for analyzing entire genomes. A comparison between GS and ES with six unrelated individuals demonstrated that an estimated 650 high quality coding single nucleotide variants (SNVs; approximately $3 \%$ of coding variants) were detected by GS but missed by ES [83]. Studies comparing GS with CMA followed by a targeted NGS gene panel, the standard of care for first-tier clinical investigation of congenital malformations and neurodevelopmental disorders, showed that GS identified clinically diagnostic genetic variants in 34\% cases, which was more than a two-fold increase compared with CMA plus a targeted NGS gene panel (13\%) [84]. For inherited retinal diseases, GS identified 14 clinically relevant genetic variants in 46 individuals; these variants included large deletions and variants in noncoding regions of the genome. These findings confirmed a molecular diagnosis for 11 of 33 individuals referred for GS who had not obtained a molecular diagnosis 
through targeted NGS gene panels, suggesting GS could result in an overall $29 \%$ increase in diagnostic yield [85].

More recently, rapid GS (rGS) has been used for infants with acute illness. rGS enables the identification of potential causes of a genetic disease or ruling out a genetic etiology for a condition within a period of $36 \mathrm{hrs}$. During a nine-month period, infants from 42 families underwent rGS for etiologic diagnosis of genetic diseases, with a diagnostic yield of $43 \%$ (18 of 42 infants). Twenty-six percent (11/42) of the infants who underwent diagnostic rGS avoided morbidity, one had a $43 \%$ reduction in likelihood of mortality, and one started palliative care. In six of the 11 infants, the changes in management because of the rGS results reduced inpatient cost by $\$ 800,000-2,000,000$ [86]. rGS provides a faster diagnosis, enabling timely precision medical interventions that can decrease the morbidity and mortality of infants with genetic diseases [87].

A meta-analysis on the cost-effectiveness of ES and GS based on 36 studies showed that a single test ranged from $\$ 555$ to 5,169 for $\mathrm{ES}$ and from $\$ 1,906$ to 24,810 for GS. Most cost-efficiency studies have concluded that ES and GS are economically superior to other testing options [88].

In summary, targeted NGS gene panels contain a set of genes specifically designed for a (or a group of) known genetic disease and can detect mosaic variants with higher confidence owing to higher sequencing depth. The diagnostic yield is relatively higher for patients with typical clinical characteristics. However, targeted panels can only detect variants in genes included in the panel and therefore are not suitable for patients with uncharacteristic manifestations and limit approaches for new discovery such as reverse genotyping. ES includes nearly all protein-coding genes, and GS covers nearly the entire genome, providing much higher diagnostic yield, but also increased cost at present.

\section{Clinical impacts}

A study examining the application of NGS for 83 patients with suspected inherited bone marrow failure syndrome demonstrated that a causal variant was detected in $18 \%$ of the patients [98]. In $20 \%$ of these patients, the results led to the initiation of a cancer surveillance program and proper family counseling [89]. In another study involving 278 infants referred for ES, $36.7 \%$ received a genetic diagnosis, and the medical management was affected in 52.0\% of the diagnosed patients [90].

Apart from the diagnostic value, the ultimate value of any diagnostic test is its impact on patient treatment, which is dependent on knowing when to order the test and whether therapeutic choices exist.

\section{APPLICATION OF NGS IN ONCOLOGY}

Cancer is a genomic disease, and the identification of characteristic genomic aberrations in cancers has become an integral part of precision medicine. NGS can be used to identify different genomic alterations commonly observed in cancer including SNVs, small indels, CNVs, and fusion genes in hematologic or solid malignancies [91-93]. Although the availability of whole genome, exome, or transcriptome sequencing has been increasing, targeted gene sequencing is the method of choice in clinical laboratories for cancer diagnosis to ensure optimal sequencing quality (read depth and coverage, variant characterization, reporting), cost-effectiveness, and turnaround time. Small NGS panels ( $<50$ genes) can be applied for specific cancers such as acute myeloid leukemia (AML) or breast cancer; however, larger NGS panels are commonly used in academic hospitals and commercial laboratories for a wide range of cancers. In our clinical laboratory in the Division of Genomic Diagnostics (DGD) at the Children's Hospital of Philadelphia (CHOP), large custom-designed NGS panels have been developed for hematologic malignancies and solid tumors for the detection of SNVs/indels, CNVs, and fusions (Fig. 1) [91, 94]. When we tested these custom-designed NGS panels on 367 pediatric cancer samples, we found that NGS panel testing had a clinical impact in $88.7 \%$ of leukemia/lymphomas, $90.6 \%$ of central nervous system (CNS) tumors, and $62.6 \%$ of non-CNS solid tumors in the cohort [91]. NGS application in clinical laboratories is regulated by a number of agencies such as the FDA, Centers for Disease Control and Prevention (CDC), and other agencies [7, 95]. The standards and guidelines for the validation of NGS panels, validation of bioinformatics pipelines, and interpretation and reporting of sequence variants in cancers were recently published [96-98].

\section{FDA-approved NGS panels in cancer}

The Thermo Fisher (Waltham, MA, USA) Oncomine Dx Target Test was the first companion diagnostic (CDx) test approved by the US FDA in June 2017. This test simultaneously evaluates variants in 23 genes associated with non-small cell lung cancer (NSCLC). The approved markers include BRAF V600E, EGFR L858R, EGFR exon 19 deletions, and ROS1 fusions for use as a CDx for specific targeted therapies [99]. Thermo Fisher is actively expanding the Oncomine Dx Target Test by validating other variants such as ERBB2 exon 20 insertions and other fu- 


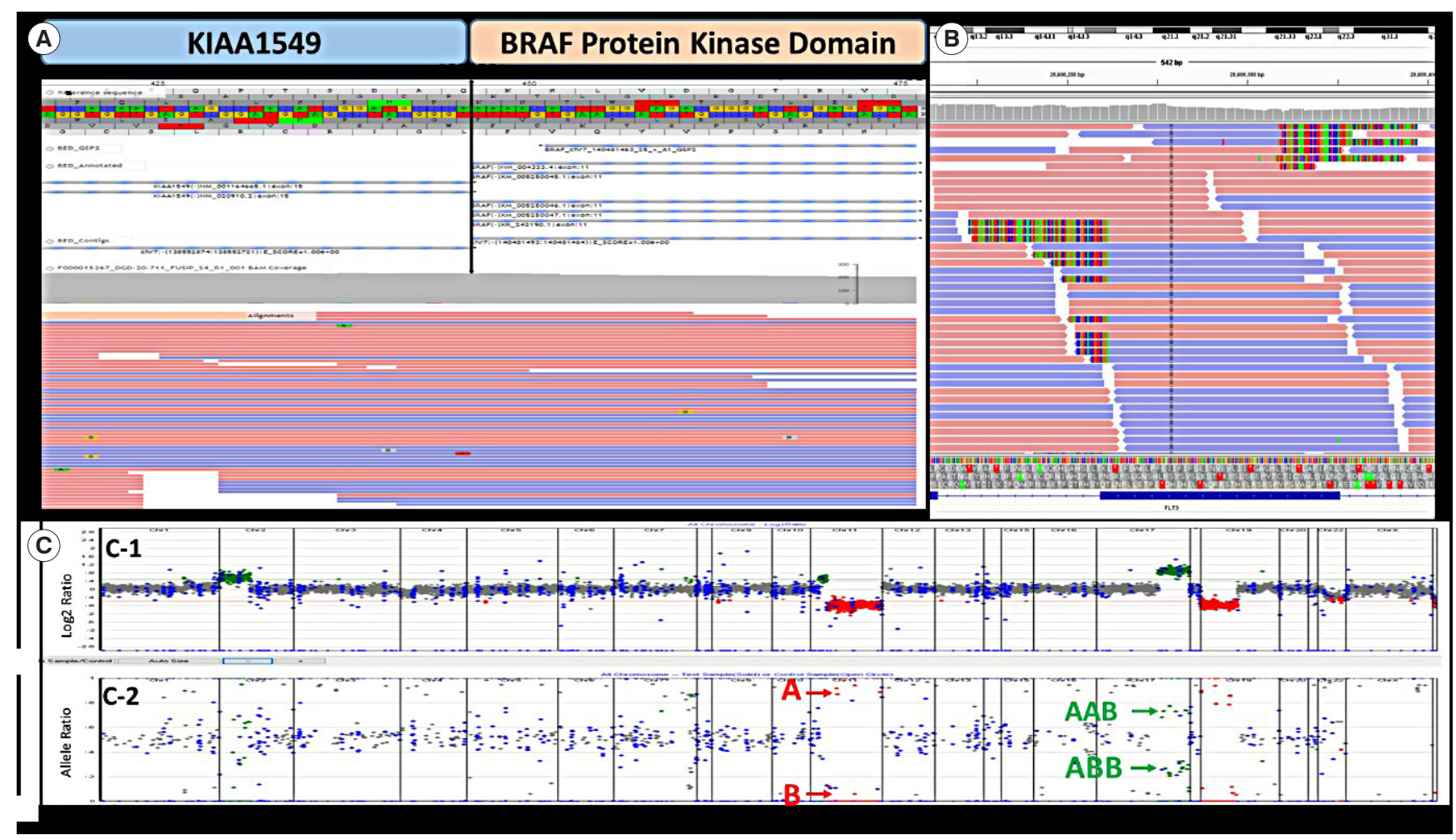

Fig. 1. Representations of genomic alterations identified by the Children's Hospital of Philadelphia Division of Genomic Diagnostics NGS tests. (A) A KIAA1549-BRAF fusion detected in the Fusion panel. Red and blue represent forward and reverse sequencing reads. (B) FLT3ITD identified in the NGS solid tumor panel. (C) CNVs identified by the NGS solid tumor panel. (C-1) CNV analysis based on reading depth. (C-2) B allele frequency analysis demonstrating SNV separation. Red arrows indicate one copy of 11q; green arrows indicate three copies of the $17 q$ genomic region.

Abbreviations: NGS, next-generation sequencing; CNV, copy number variation; SNV, single-nucleotide variation.

sions including ALK and RET [100]. The Oncomine Dx Target Test has received positive reimbursement decisions from the CMS and from large commercial health insurers in USA. It has been adopted for use by several national reference laboratories.

The US FDA approved Memorial Sloan Kettering-Integrated Mutation Profiling of Actionable Cancer Targets (MSK-IMPACT) panel, developed by the Memorial Sloan Kettering Cancer Center, and the FoundationOne CDx (F1CDx), developed by Foundation Medicine, for in vitro diagnosis via detection of genetic variants in November 2017 [101-103]. The MSK-IMPACT test detects SNVS, indels, and microsatellite instability (MSI) in 468 unique genes by sequencing both tumor samples and matched normal samples from the same patient with solid malignant neoplasms to detect genetic alterations that might help guide treatment options. F1CDx detects SNVs, indels, limited CNVs, and gene rearrangements in 324 genes and two genomic signatures, including MSI and tumor mutational burden (TMB), in any solid tumor to identify patients who may benefit from treatment with targeted therapies. Additionally, F1CDx was approved by the US FDA in 2019 to be used as a CDx for olaparib for first line maintenance therapy in BRCA-mutated advanced ovarian cancer [104]. The F1CDx test has also been accepted by the CMS. MSK-IMPACT and F1CDx are single-site tests performed at the Memorial Sloan Kettering Cancer Center and Foundation Medicine, respectively.

The NantHealth Omics Core test was approved by the US FDA in November 2019. It is a WES platform to report TMB and somatic alterations (SNVs and indels) in 468 cancer-relevant genes (https://www.accessdata.fda.gov/cdrh_docs/reviews/ K190661.pdf). The Illumina TruSight Oncology 500 (TSO 500) test was launched in October 2018. It targets 523 genes for SNV and indel detection and 55 genes for fusion and splice variant detection. It can also detect immunotherapy-associated biomarkers such as TMB and MSI; Illumina is seeking US FDA approval of this test as a CDx. MI Transcriptome CDx (Caris Life Sciences, Irving, Texas, USA) is an NGS test using RNA from formalin-fixed paraffin embedded tumor tissue to detect structural rearrangements and measure gene expression in cancer patients; it has 
received a breakthrough device designation from the US FDA for the detection of FGFR biomarkers including gene fusions in solid tumors (https://fdahealthnews.com/stories/512479753).

\section{Application of NGS in cancer diagnosis, prognosis, and therapeutics}

Disease-specific biomarkers

In addition to US FDA-approved NGS panels, many other commercial or custom-designed NGS panels are being used in clinical laboratories, with an increasing number of identified biomarkers for cancer diagnosis, prognosis, and therapeutics. For example, in normal karyotype $A M L$, the most frequently mutated genes include NPM1, CEBPA, FLT3, DNMT3A, TET2, IDH1, IDH2, NRAS, ASXL1, KMT2A, WT1, and RUNX1 [105]. NPM1 is the most frequently mutated gene in adult type $A M L$, and NPM1 mutations are associated with favorable outcomes in the absence of concurrent DNTM3A and FLT3-ITD mutations [106]. CEBPA mutations are commonly bi-allelic and have been associated with a favorable outcome in AML [107]. RUNX1 mutations have been associated with worse overall survival [108]. Patients with FLT3-ITD mutations often have an increased risk of relapse and shorter overall survival compared with patients without the mutation [109].

In 2017, the US FDA approved midostaurin, a multi-targeted protein kinase inhibitor, for treating newly diagnosed adult AML patients with FLT3 mutations. In 2017, the US FDA also approved enasidenib for the treatment of relapsed or refractory adult AML with an IDH2 gene mutation, while in 2018 it approved ivosidenib as the first treatment for adult patients with relapsed/refractory AML and an IDH1 mutation [110]. DNMT3A mutations tend to be associated with shortened overall survival [111], and TET2 mutations are often associated with a poor prognosis in cytogenetically normal AML [112-114]; however, patients with TET2 mutations may respond to hypomethylating agents [115]. Mutations in ASXL1, KMT2A, or TP53 are generally associated with poor prognosis [116]. The 2017 World Health Organization (WHO) classification recognizes AML with mutated NPM1, CEBPA, and RUNX1 as specific entities [117].

Another successful example of clinical NGS application is in lung cancer. Certain mutations in several genes, such as EGFR, ALK, and ROS1, are targetable driver mutations [118-120]. There are several US FDA-approved EGFR inhibitors, such as afatinib, gefitinib, erlotinib, and osimertinib, for NSCLC patients with these mutations. Lung cancer patients with $A L K$ rearrangements (e.g. EML4-ALK) may benefit from US FDA-approved ALK-inhibitors, including crizotinib, alectinib, and ceritinib [121].
ROS1 mutations are present in $1-2 \%$ of NSCLC patients who may be sensitive to crizotinib and entrectinib, approved by the US FDA in 2016 and 2019, respectively [122, 123]. According to the 2018 guidelines of the College of American Pathologists, the International Association for the Study of Lung Cancer, and the Association for Molecular Pathology, testing for mutations in EGFR, ALK, and ROS1 is required for all advanced-stage lung cancers; if these are negative, additional targetable alterations in $B R A F, M E T, R E T$, ERBB2, and KRAS can be tested [124]. The use of NGS technology in lung cancer tests has proven reliable, cost-effective, and efficient [92].

\section{Cancer type-agnostic biomarkers}

In addition to disease-specific biomarkers, a few pan-cancer biomarkers have been identified, including MSI, TMB, and neurotrophic tropomyosin-related kinase (NTRK). MSI is caused by the inactivation of the DNA mismatch repair (MMR) system and has been found in many types of primary cancers [125, 126]. In May 2017, the US FDA approved the PD-1 inhibitor pembrolizumab (Keytruda) for treating adult and pediatric patients with unresectable or metastatic solid tumors that have been identified as MSI-high (MSI-H) or MMR deficient (dMMR) [127]. This was the first time that a cancer treatment was approved on the basis of a common biomarker, irrespective of the tissue of origin. Furthermore, the US FDA approved other drugs, including nivolumab (Opdivo) and combination of nivolumab and ipilimumab (Yervoy, a cytotoxic T-lymphocyte-associated protein 4 (CTLA-4 inhibitor)), for treating adult and pediatric patients with MSI-H or dMMR metastatic colorectal cancer [128, 129].

NTRK is the second US FDA-approved tissue-agnostic biomarker for cancer treatment, which is based on the presence of NTRK fusions. Fusions involving members of the NTRK oncogene family, NTRK1/NTRK2/NTRK3, are the most prevalent in rare adult cancer types and a broad range of pediatric cancers, with increased frequency in highly aggressive cancers such as glioblastoma [130, 131]. In November 2018, the US FDA approved larotrectinib (VITRAKVI), an oral and selective tropomyosin receptor kinase (TRK) inhibitor, for treating adult and pediatric patients with metastatic or unresectable solid tumors that have an NTRK fusion without a known acquired resistance mutation [132, 133]. In August 2019, the US FDA granted approval for another TRK inhibitor, entrectinib (ROZLYTREK), for adults and pediatric patients ( $\geq 12$ years of age) with metastatic or unresectable solid tumors that have an NTRK fusion without a known acquired resistance mutation. Entrectinib was also approved for adults with metastatic NSCLC whose tumors are 
ROS1-positive [134, 135].

TMB is another tissue-agnostic marker for potential response to immunotherapy. TMB can be used to identify patients most likely to benefit from immunotherapy across a wide range of cancer types [136, 137]. TMB can be accurately measured through NGS targeting a large panel of gene (e.g., F1CDx), ES (e.g. NantHealth Omics Core), or GS. Calculation of TMB and identification of MSI status can be simultaneously performed in a single NGS-based test.

\section{Clinical trials}

Another application of NGS in oncology is identifying and enrolling patients into the appropriate clinical trials. There are two kinds of clinical trials: umbrella trials and bucket trials (also known as basket trials) [138, 139]. An umbrella trial enrolls patients with a type of morphologically defined cancer and assigns them to a treatment arm on the basis of the genetic mutations detected in their cancer; many different treatment arms exist under the umbrella of a single trial. In a basket trial, patients with different cancers, but sharing the same genetic abnormality, are enrolled to test a new drug against the common genetic alteration. An example of a basket trial is the ongoing NCI-MATCH (National Cancer Institute -Molecular Analysis for Therapy Choice) trial launched in 2015 by the US NCl [140]. Thousands of cancer biopsies from patients undergo NGS to identify genetic abnormalities that may respond to selected targeted therapies.

\section{Application of NGS in minimal residual disease (MRD) monitoring and liquid biopsy}

MRD refers to the small number of cancer cells that remain in the body during or after cancer treatment. MRD can be used to measure the effectiveness of treatment, predict the risk of relapse, confirm or monitor remission, and potentially identify an early relapse of the cancer [141]. The most widely used tests for measuring MRD include flow cytometry, real-time quantitative PCR, digital PCR, and NGS. Flow cytometry or PCR-based tests can usually measure MRD down to 1 in 10,000 or 1 in 100,000 cells [142, 143]. The ClonoSEQ test, developed by Adaptive Biotechnologies (Seattle, WA, USA), is an NGS-based test for assessing and monitoring MRD in patients with multiple myeloma and B-cell acute lymphoblastic leukemia. It was approved by the US FDA in 2018 and has been covered by Medicare and private health insurers since 2019 [144, 145]. This test detects as few as one cancer cell in one million healthy $\left(<10^{-6}\right)$ cells. The company is also validating this test for other disorders, such as chronic lymphocytic leukemia and non-Hodgkin's lym- phoma. Recently, the US FDA issued draft guidelines on the use of MRD assessment in trials involving patients with hematologic malignancies [6].

Cancer heterogeneity, limited cancer biopsy samples, and invasive procedures are some of the challenges in molecular diagnostics and disease monitoring of solid tumors [146]. Liquid biopsy, which tests circulating cancer cells, circulating cell-free cancer DNA/RNA, or exosomes in blood or other bodily fluids, such as urine and cerebrospinal fluid (CSF), shows great promise for MRD detection, real-time monitoring of disease progression, therapy selection, and cancer diagnosis during early stages of the disease [147-150]. In 2016, the US FDA approved the Cobas EGFR Mutation Test v2, a PCR-based liquid biopsy test from Roche, for detecting specific EGFR mutations in blood samples. This test can be used to identify patients with metastatic NSCLC who would be eligible for treatment with erlotinib (Tarceva) [151]. Several large NGS-based liquid biopsy tests are available, including Guardant360 (Guardant Health) and FoundationOne Liquid (Foundation Medicine); however, these have yet to be approved by the US FDA [152]. The FDA has granted a breakthrough device designation for several blood-based cancer tests, such as the Grail multi-cancer blood test for early cancer detection [153] and the PapGene test for detecting ovarian and pancreatic cancers based on a combination of circulating cancer DNA (ctDNA) and protein biomarkers [154]. Other investigational liquid biopsy tests include TruSight Oncology 500 ctDNA (Illumina), Oncomine Pan-Cancer Cell-Free Assay (Thermo Fisher), and CancerSEEK (Thrive Earlier Detection Corp, Cambridge, MA, USA) [155].

According to the joint review issued by the American Society of Clinical Oncology and the College of American Pathologists, more evidence is needed to demonstrate the clinical utility of liquid biopsy [156]. Additional challenges need to be addressed before a wide application of liquid biopsy in clinical settings. For example, the fraction of cancer-derived DNA in blood plasma samples is generally low; therefore, modified sample preparation methods and much deeper sequence coverage are needed to achieve sufficient sensitivity. Furthermore, clonal hematopoiesis may potentially confound the results of liquid biopsy tests [157].

\section{CLINICAL APPLICATIONS FOR DIAGNOSIS OF INFECTIOUS DISEASES}

Globally, infectious diseases remain one of the most significant overall causes of morbidity and mortality [158]. Proper and accurate diagnosis of a pathogen is critical for patient treatment, 
as a delayed or incorrect diagnosis can lead to a multitude of adverse events including unnecessary use or misuse of antibiotics, increased healthcare costs, and worsened patient outcomes [159-162]. Many of these issues are exacerbated in settings, such as poor and under-served areas, in which tools for rapid, accurate diagnoses are limited [163].

Sequencing bacterial DNA and RNA has been used for decades to identify casual pathogens and resistance genes in clinical isolates and even before the onset of NGS, could yield rapid results with high specificity $[164,165]$. However, with the advance of NGS technologies, clinicians and laboratory professionals have seen tremendous growth and opportunity for using sequencing as a front-line diagnostic tool. Below, we summarize and briefly highlight the current applications of NGS for infectious diseases including a brief comparison of NGS methods, epidemiological surveillance, identification of pathogens and their resistance markers for diagnosis and treatment, and the importance of the host microbiome.

NGS strategies for infectious diseases

Before discussing the utility of NGS in clinical care of infectious disease, it is important to understand the three main types of NGS methods and how they differ. Targeted NGS uses panels of known pathogen sequences to screen clinical isolates. The panels can be specific for or target multiple types of pathogens including bacteria [166], viruses [167], and even eukaryotic organisms [168]. These panels can also target pathogens known to be involved in particular illnesses, such as gastrointestinal [168] or respiratory [169] diseases, and have been optimized for use with specific sample types, such as CSF [170]. The advantages of these panels are their high specificity, sensitivity, rapid turnaround time, and ability to sequence directly from a host isolate [166, 168, 170]. However, the downsides include their limited scope and inability to identify novel pathogens or antibiotic resistance markers.

In the case of bacterial samples, WGS enables the sequencing of an entire pathogen genome including plasmids. This broad sequencing allows for the identification of antibiotic resistance profiles, which can be used to inform first-line drug use decisions [171]. The drawback of WGS for bacterial samples is that it usually requires a separate culture step to ensure the sample is free of contaminant or commensal bacteria; however, sequencing directly from a host isolate and skipping culture has been performed with targeted enrichment [172]. Furthermore, while WGS datasets accurately define known drug resistance markers, the discovery of novel mutations and their effects on phenotype bring added uncertainty to the test [173, 174].

Metagenomic NGS (mNGS) can use samples directly obtained from a patient and amplify the sequences of all organisms in the sample, including host sequences. This unbiased approach allows for the detection of multiple types of pathogens in one sample (and even the host response to them) and can be particularly useful when targeted or less comprehensive tests are not diagnostic [175-177]. Furthermore, mNGS can detect pathogen sequences that comprise a very small portion of the overall sequenced reads; such low-level sequences can easily be missed by other methodologies [178]. However, there are significant drawbacks to using an mNGS approach, which include the cost and complexity of the process, as well as the need for optimization and standardization of each step in the test, from sample preparation to data analysis [179-181]. Owing to its unbiased nature, $\mathrm{mNGS}$ requires additional considerations such as the low ratio of pathogen to host DNA or RNA; unless the host genome or transcriptome are also being analyzed, the host DNA/RNA should be removed [182]. In addition, the presence of commensal bacteria in host samples [183] and contaminated laboratory reagents [184-186] can also confound testing, leading to incorrect results.

\section{Epidemiology and public health}

During infectious disease outbreaks, it is critical to rapidly track the transmission, spread, and evolution of pathogens; NGS has been playing an increasingly critical role in these processes. One case that highlights the potential speed of NGS in the field is the West Africa Ebola virus (EBV) outbreak of 2015. Researchers utilized third generation Nanopore technology (as described in the NGS Technologies section above) to track EBV transmission of separate viral lineages across countries by monitoring mutation rates [187]. Using a MinION sequencer (Oxford Nanopore Technologies), researchers were able to sequence over 140 EBV samples directly in the field [187]. Sequencing on the machine itself generally took less than one hr and with cloud-based computing, data were ready to be analyzed in less than a day. Only days after the outbreak of new coronavirus associated pneumonia in Wuhan, China, the sequence of the new coronavirus, SARS-CoV-2, was determined using mNGS, which facilitated disease diagnosis and surveillance, and the development of effective drugs for disease treatment and vaccines for prevention [188].

NGS has also facilitated disease outbreak tracking in clinical settings, particularly in cases of healthcare-acquired infections. In one study, the spread of adenovirus in a neonatal intensive 
care unit was linked to eye examinations, based on confirmation that the exact viral sequence was found in both affected patients and the equipment used during their examinations [189]. In another hospital, an outbreak of a fungal bloodstream infection in 18 patients receiving anti-nausea medication was found to be connected to contaminated medication, with all patients and contaminated containers testing positive for an identical pathogen identified by WGS [190]. In another case of unexpected transmission, researchers proposed a reasonable hypothesis for the spread of a highly resistant Klebsiella pneumonia strain based on WGS, which linked all cases to an index patient discharged three weeks before any others demonstrated symptoms [191]. NGS can also provide critical insights into the diversity of clinical isolates and can group strains based on their genetic profiles during outbreaks, which is particularly important in the context of identifying emergent resistant or virulent strains [192, 193].

Finally, while not directly related to clinical care, NGS is also advancing and improving procedures for public health related surveillance. WGS is currently being used alongside traditional methods for tracking and sourcing foodborne illnesses, showing improved speed and rates of detection [194-196]. Furthermore, NGS has proven valuable in monitoring the most prevalent strains of influenza, which has important impacts on the development of annual vaccines [197, 198].

\section{Pathogen identification and diagnosis}

Numerous examples in the literature describe the use of NGS to identify bacterial, viral, or eukaryotic pathogens in a wide range of sample types including synovial fluid, CSF, feces, corneal tissue, blood, plasma, and nasopharyngeal swabs [199-206]. Rather than describing these routine applications of NGS in detail, we will instead highlight a few cases that show the advantages of using NGS tests as opposed to traditional laboratory practices.

Traditional diagnostic laboratory methods, such as culturebased or PCR tests, are generally reliable and cost-effective for common pathogens; however, NGS and mNGS can specifically provide tremendous value in cases, where there is no a priori knowledge of the pathogen. One extreme example is a case of an adolescent with severe combined immunodeficiency who presented with infection symptoms for months without a diagnosis [207]. Nearly 40 different tests using multiple sample types, ranging from culture to PCR-based methods, proved nondiagnostic. Finally, the use of mNGS with CSF identified a very low number of reads that matched to Leptospira santarosai, demonstrating proof of a specific bacterial infection. Following this discovery, the patient was administered the appropriate antibiotics and responded to the treatment.

In another case, an mNGS approach was used to identify a likely cause of death in three men, who developed nearly identical CNS symptoms before dying, but showed no evidence of an infectious pathogen using multiple diagnostic tests [208]. The three men were squirrel breeders, had shared squirrels for breeding, and all three had previously been exposed to bites or scratches. Through mNGS of multiple tissue types isolated from a squirrel handled by one of the patients, the researchers identified a low level of sequences that corresponded to the bornavirus family, though this virus was ultimately determined to be novel based on phylogenetic studies. The bornavirus was confirmed using quantitative reverse transcription PCR in both the squirrel and patient brain tissue, as well as by immunohistochemical staining of patient tissues. There are multiple other examples of cases, where NGS found an unexpected or previously undiagnosed pathogen including eukaryotic organisms such as amoebae [209, 210].

In many settings, fast detection of the pathogen, as well as its associated resistance or virulence markers, is extremely important for appropriate and timely treatment; rGS can identify treatment options faster than conventional methods. Nanopore sequencing, which is as fast, or faster than standard approaches, has been used to identify pathogens, as well as antibiotic resistance markers [211, 212]. At one institution, Nanopore sequencing was found to shorten the average time to appropriate antibiotic therapy in pneumonia patients by roughly $24 \mathrm{hrs} \mathrm{com-}$ pared with standard methods, while delivering results in eight hrs post sequencing [213]. NGS is particularly helpful in situations where results are delayed or are non-diagnostic by culture, and can detect antimicrobial resistance or virulence markers at low frequencies, while still demonstrating sensitivity and specificity comparable to standard practices [172, 214-218].

NGS can also resolve discrepancies between standard culture-based and molecular-based diagnostic approaches and identify multiple organism co-infections, which may confound standard testing results [219, 220]. Furthermore, culture may be less effective as a diagnostic test when used to identify pathogens from patients already treated with antibiotics; in one study NGS showed significantly higher sensitivity than culture methods in patients with prior antibiotic exposure [221]. Finally, NGS using cell-free DNA in urine or blood has proven effective for diagnosing additional pathogens in cases where culturebased methods have failed [175, 204, 205]. 
Integrated sequencing of pathogens and the host

Up until now, we have focused on the sequencing and identification of infectious organisms. However, using datasets of the host's own microbiome, as well as changes in host gene expression, can greatly aid the predictive value of testing. One study examining lower respiratory tract infections showed that an approach combining the gene expression signature of a patient's immune response measured by profiling the host transcriptome via RNA-sequencing, alongside mNGS to identify and discern between the patient's own commensal flora and pathogen genomes, was able to accurately identify the causative pathogen and achieve high sensitivity and specificity, with a true negative predictive value of $100 \%$ [222]. In addition to aiding in the interpretation of diagnoses, the host microbiome can also provide insight into the general wellness of a patient. For example, virome sequencing in immunocompromised patients post-organ or stem cell transplant can gauge the competency of the host immune system, as viral load can increase with use of immunosuppressant drugs [223-225]. Changes in the diversity of commensal bacterial flora can highlight disease onset or progression [226, 227]. Conversely, rescue of that diversity has been monitored using NGS by comparing results from a phylogenetic microarray alongside improved symptoms in patients with Clostridium difficile infections who were administered treatments such as fecal transplants [228]. Overall, the application of NGS has demonstrated diagnostic utility in infectious diseases, and further advancements in sequencing technologies will open new avenues for integrating both host and pathogen sequencing data, to provide a more holistic diagnosis and inform clinical management.

\section{CHALLENGES AND FUTURE PERSPECTIVES}

Commonly used NGS technologies have limitations such as short reads and relying on clonal PCR to generate enough signals for detection. New technologies with long reads and single molecular sequencing (e.g., Pacific Biosystems and Oxford Nanopore) would theoretically be better and require less starting material; however, their high error rate prevents them from becoming the method of choice. GS is predicated to play an increasingly important role in laboratory medicine, as it does not require an upfront enrichment step and produces uniform coverage of the whole genome; however, data analysis, especially structural variant analysis, variant interpretation, and data storage, remains arduous in GS [229, 230]. In oncology, cancer heterogeneity is a challenge for sampling, variant detection, variant interpretation, and treatment recommendations. New methods, such as single cell sequencing [231] and liquid biopsy, are promising for addressing this issue. Germline alterations are also confounding issues in somatic cancer diagnostics; sequencing matched cancer and normal tissues simultaneously from the same patient is a plausible solution, although obtaining matched normal tissue has proven difficult in certain clinical situations [232].

The implementation of NGS tests in clinical diagnostic laboratories requires many resources [233]. Test validation, bioinformatics support, and data storage according to the guidelines are required before NGS test implementation and these are cost prohibitive for many small laboratories. Additionally, the current cost of clinical NGS tests remains high, limiting the usage of large panel testing, ES, and GS in cancer. Another obstacle of NGS application in laboratory medicine is insurance coverage. In 2018, the CMS finalized the National Coverage Determination, which covers NGS tests for patients with advanced cancer (https://www. cms.gov/medicare-coverage-database/details/nca-tracking-sheet. aspx?NCAld =296). In 2019, the CMS proposed a new national coverage policy for germline NGS panels for cancer patients, which will be finalized in 2020 (https://www.cms.gov/newsroom/ press-releases/cms-expands-coverage-next-generation-sequencingdiagnostic-tool-patients-breast-and-ovarian-cancer).

\section{CONCLUSIONS}

NGS is a breakthrough technology that opens new opportunities for molecular diagnostics. Many clinical laboratories have already adopted NGS technology to identify causal variants for the diagnosis of constitutional disorders, genomic profiling for precision oncology, and pathogen detection for infectious diseases. The NGS technologies and bioinformatics tools will continue to evolve and become the major diagnostic means and standard of care for genomic analysis to meet the ever-increasing demands of precision medicine.

\section{ACKNOWLEDGEMENTS}

None.

\section{AUTHOR CONTRIBUTIONS}

YZ, FX, JW, JS, and MML were contributors in writing the manuscript. All authors read and approved the final manuscript. 


\section{CONFLICTS OF INTEREST}

None declared.

\section{RESEARCH FUNDING}

This study was supported in part by the Department of Pathology and Laboratory Medicine, Children's Hospital of Philadelphia, University of Pennsylvania, Perelman School of Medicine.

\section{ORCID}

$\begin{array}{ll}\text { Yiming Zhong } & \text { https://orcid.org/0000-0002-6596-6952 } \\ \text { Feng Xu } & \text { https://orcid.org/0000-0002-7227-7426 } \\ \text { Jinhua Wu } & \text { https://orcid.org/0000-0002-8511-3949 } \\ \text { Jeffrey Schubert } & \text { https://orcid.org/0000-0002-2927-0229 } \\ \text { Marilyn M. Li } & \text { https://orcid.org/0000-0002-4253-2369 }\end{array}$

\section{REFERENCES}

1. Goodwin S, McPherson JD, McCombie WR. Coming of age: ten years of next-generation sequencing technologies. Nat Rev Genet 2016;17: 333-51.

2. Schwarze K, Buchanan J, Fermont JM, Dreau H, Tilley MW, Taylor JM, et al. The complete costs of genome sequencing: a microcosting study in cancer and rare diseases from a single center in the United Kingdom. Genet Med 2020;22:85-94.

3. Lalonde E, Wertheim G, Li MM. Clinical impact of genomic information in pediatric leukemia. Front Pediatr 2017;5:263.

4. Gutowska-Ding MW, Deans ZC, Roos C, Matilainen J, Khawaja F, Brugger $\mathrm{K}$, et al. One byte at a time: evidencing the quality of clinical service next-generation sequencing for germline and somatic variants. Eur J Hum Genet 2020;28:202-12.

5. Gwinn M, MacCannell D, Armstrong GL. Next-generation sequencing of infectious pathogens. JAMA 2019;321:893-4.

6. Hoadley KA, Yau C, Hinoue T, Wolf DM, Lazar AJ, Drill E, et al. Cell-oforigin patterns dominate the molecular classification of 10,000 tumors from 33 types of cancer. Cell 2018;173:291-304.e6.

7. Luh $F$ and Yen Y. FDA guidance for next generation sequencing-based testing: balancing regulation and innovation in precision medicine. NPJ Genom Med 2018;3:28.

8. Allegretti M, Fabi A, Buglioni S, Martayan A, Conti L, Pescarmona E, et al. Tearing down the walls: FDA approves next generation sequencing (NGS) assays for actionable cancer genomic aberrations. J Exp Clin Cancer Res 2018;37:47.

9. Yuan M, Huang LL, Chen JH, Wu J, Xu Q. The emerging treatment landscape of targeted therapy in non-small-cell lung cancer. Signal Transduct Target Ther 2019;4:61.

10. Mardis ER. A decade's perspective on DNA sequencing technology. Nature 2011;470:198.

11. Mardis ER. DNA sequencing technologies: 2006-2016. Nature Protoc 2017;12:213

12. Shendure J and Ji H. Next-generation DNA sequencing. Nature Biotechnol 2008;26:1135.
13. Glenn TC. Field guide to next-generation DNA sequencers. Molecular Ecol Resour 2011;11:759-69.

14. Sanger F, Donelson J, Coulson A, Kössel H, Fischer D. Use of DNA polymerase I primed by a synthetic oligonucleotide to determine a nucleotide sequence in phage f1 DNA. Proc Natl Acad Sci U S A 1973; 70:1209-13.

15. Sanger F, Donelson J, Coulson A, Kössel H, Fischer D. Determination of a nucleotide sequence in bacteriophage $\mathrm{f1}$ DNA by primed synthesis with DNA polymerase. J Mol Biol 1974;90:315-33.

16. Sanger $F$ and Coulson AR. A rapid method for determining sequences in DNA by primed synthesis with DNA polymerase. J Mol Biol 1975; 94:441-8.

17. Lander ES, Linton LM, Birren B, Nusbaum C, Zody MC, Baldwin J, et al. Initial sequencing and analysis of the human genome. Nature 2001; 409:860-901.

18. Archer J, Weber J, Henry K, Winner D, Gibson R, Lee L, et al. Use of four next-generation sequencing platforms to determine HIV-1 coreceptor tropism. PLoS One 2012;7:e49602.

19. Burghel GJ, Hurst CD, Watson CM, Chambers PA, Dickinson H, Roberts $P$, et al. Towards a next-generation sequencing diagnostic service for tumour genotyping: A comparison of panels and platforms. Biomed Res Int 2015;2015:478017.

20. Mardis ER. New strategies and emerging technologies for massively parallel sequencing: applications in medical research. Genome Med 2009; 1:40.

21. Chang F and Li MM. Clinical application of amplicon-based next-generation sequencing in cancer. Cancer Genet 2013;206:413-9.

22. Mardis ER. Sequencing the AML genome, transcriptome, and epigenome. Sem Hematol 2014;51:250-8.

23. Misyura M, Zhang T, Sukhai MA, Thomas M, Garg S, Kamel-Reid S, et al. Comparison of next-generation sequencing panels and platforms for detection and verification of somatic tumor variants for clinical diagnostics. J Mol Diagn 2016;18:842-50.

24. Fernandez-Cuesta L, Sun R, Menon R, George J, Lorenz S, MezaZepeda LA, et al. Identification of novel fusion genes in lung cancer using breakpoint assembly of transcriptome sequencing data. Genome Biol 2015;16:7

25. Tilgner H, Raha D, Habegger L, Mohiuddin M, Gerstein M, Snyder M. Accurate identification and analysis of human mRNA isoforms using deep long read sequencing. G3 (Bethesda) 2013;3:387-97.

26. Niedringhaus TP, Milanova D, Kerby MB, Snyder MP, Barron AE. Landscape of next-generation sequencing technologies. Anal Chem 2011;83:4327-41.

27. Dressman D, Yan H, Traverso G, Kinzler KW, Vogelstein B. Transforming single DNA molecules into fluorescent magnetic particles for detection and enumeration of genetic variations. Proc Natl Acad Sc USA 2003;100:8817-22.

28. Ansorge WJ. Next-generation DNA sequencing techniques. N Biotechnol 2009;25:195-203.

29. Metzker ML. Sequencing technologies-the next generation. Nat Rev Genet 2010;11:31.

30. Margulies M, Egholm M, Altman WE, Attiya S, Bader JS, Bemben LA, et al. Genome sequencing in microfabricated high-density picolitre reactors. Nature 2005;437:376.

31. Huse SM, Huber JA, Morrison HG, Sogin ML, Welch DM. Accuracy and quality of massively parallel DNA pyrosequencing. Genome Biol 2007;8:R143.

32. Rothberg JM, Hinz W, Rearick TM, Schultz J, Mileski W, Davey M, et al. An integrated semiconductor device enabling non-optical genome sequencing. Nature 2011;475:348. 
33. Liu L, Li Y, Li S, Hu N, He Y, Pong R, et al. Comparison of next-generation sequencing systems. J Biomed Biotechnol 2012;2012:251364.

34. Mason CE and Elemento O. Faster sequencers, larger datasets, new challenges. Genome Biol 2012;13:314.

35. Boland JF, Chung CC, Roberson D, Mitchell J, Zhang X, Im KM, et al. The new sequencer on the block: comparison of Life Technology's Proton sequencer to an Illumina HiSeq for whole-exome sequencing. Human Genet 2013;132:1153-63.

36. Mehrotra M, Duose DY, Singh RR, Barkoh BA, Manekia J, Harmon $M A$, et al. Versatile ion S5XL sequencer for targeted next generation sequencing of solid tumors in a clinical laboratory. PLoS One 2017;12: e0181968.

37. Franzosa EA, Hsu T, Sirota-Madi A, Shafquat A, Abu-Ali G, Morgan XC, et al. Sequencing and beyond: integrating molecular 'omics' for microbial community profiling. Nat Rev Microbiol 2015;13:360-72.

38. Wang Z, Gerstein M, Snyder M. RNA-Seq: a revolutionary tool for transcriptomics. Nat Rev Genet 2009;10:57-63.

39. Wilhelm BT and Landry JR. RNA-Seq-quantitative measurement of expression through massively parallel RNA-sequencing. Methods 2009; 48:249-57.

40. Zhao S, Fung-Leung WP, Bittner A, Ngo K, Liu X. Comparison of RNASeq and microarray in transcriptome profiling of activated $T$ cells. PLoS One 2014;9:e78644.

41. Zhou J, He Z, Yang Y, Deng Y, Tringe SG, Alvarez-Cohen L. Highthroughput metagenomic technologies for complex microbial community analysis: open and closed formats. mBio 2015;6:e02288-14 .

42. Chen G, Chakravarti N, Aardalen K, Lazar AJ, Tetzlaff MT, Wubbenhorst $\mathrm{B}$, et al. Molecular profiling of patient-matched brain and extracranial melanoma metastases implicates the PI3K pathway as a therapeutic target. Clin Cancer Res 2014;20:5537-46.

43. Hamid O, Robert C, Daud A, Hodi FS, Hwu WJ, Kefford R, et al. Safety and tumor responses with lambrolizumab (anti-PD-1) in melanoma. N Engl J Med 2013;369:134-44.

44. Bentley DR, Balasubramanian S, Swerdlow HP, Smith GP, Milton J, Brown CG, et al. Accurate whole human genome sequencing using reversible terminator chemistry. Nature 2008;456:53-9.

45. Van Dijk EL, Auger H, Jaszczyszyn Y, Thermes C. Ten years of nextgeneration sequencing technology. Trends Genet 2014;30:418-26.

46. Ravi RK, Walton K, Khosroheidari M. MiSeq: A next generation sequencing platform for genomic analysis. Methods Mol Biol 2018;1706: 223-32.

47. Berlin K, Koren S, Chin C-S, Drake JP, Landolin JM, Phillippy AM. Assembling large genomes with single-molecule sequencing and localitysensitive hashing. Nature Biotechnol 2015;33:623-30.

48. Eid J, Fehr A, Gray J, Luong K, Lyle J, Otto G, et al. Real-time DNA sequencing from single polymerase molecules. Science 2009;323:133-8.

49. Ferrarini M, Moretto M, Ward JA, Šurbanovski N, Stevanović V, Giongo L, et al. An evaluation of the PacBio RS platform for sequencing and de novo assembly of a chloroplast genome. BMC Genomics 2013;14:670.

50. van Dijk EL, Jaszczyszyn Y, Naquin D,Thermes C. The third revolution in sequencing technology. Trends Genetics 2018;34:666-81.

51. Travers KJ, Chin C-S, Rank DR, Eid JS, Turner SW. A flexible and efficient template format for circular consensus sequencing and SNP detection. Nucleic Acids Res 2010;38:e159-e.

52. Coupland P, Chandra T, Quail M, Reik W, Swerdlow H. Direct sequencing of small genomes on the Pacific Biosciences RS without library preparation. Biotechniques 2012;53:365-72.

53. Baker EAG, Goodwin S, McCombie WR, Ramos OM. SiLiCO: a simulator of long read sequencing in PacBio and Oxford Nanopore. BioRxiv 2016:076901.
54. Korlach J, Marks PJ, Cicero RL, Gray JJ, Murphy DL, Roitman DB, et al. Selective aluminum passivation for targeted immobilization of single DNA polymerase molecules in zero-mode waveguide nanostructures. Proc Natl Acad Sci U S A 2008;105:1176-81.

55. Quail MA, Smith M, Coupland P, Otto TD, Harris SR, Connor TR, et al. A tale of three next generation sequencing platforms: comparison of Ion Torrent, Pacific Biosciences and Illumina MiSeq sequencers. BMC Genomics 2012;13:341.

56. Brown SD, Nagaraju S, Utturkar S, De Tissera S, Segovia S, Mitchell W, et al. Comparison of single-molecule sequencing and hybrid approaches for finishing the genome of Clostridium autoethanogenum and analysis of CRISPR systems in industrial relevant Clostridia. Biotechnol Biofuels 2014;7:40.

57. Weirather JL, Afshar PT, Clark TA, Tseng E, Powers LS, Underwood JG, et al. Characterization of fusion genes and the significantly expressed fusion isoforms in breast cancer by hybrid sequencing. Nucleic Acids Res 2015;43:e116.

58. Bashir A, Klammer AA, Robins WP, Chin C-S, Webster D, Paxinos E, et al. A hybrid approach for the automated finishing of bacterial genomes. Nature Biotechnol 2012;30:701.

59. Koren S, Schatz MC, Walenz BP, Martin J, Howard JT, Ganapathy G, et al. Hybrid error correction and de novo assembly of single-molecule sequencing reads. Nature Biotechnol 2012;30:693.

60. Miller DT, Adam MP, Aradhya S, Biesecker LG, Brothman AR, Carter NP, et al. Consensus statement: chromosomal microarray is a first-tier clinical diagnostic test for individuals with developmental disabilities or congenital anomalies. Am J Hum Genet 2010;86:749-64.

61. Yang Y, Muzny DM, Reid JG, Bainbridge MN, Willis A, Ward PA, et al. Clinical whole-exome sequencing for the diagnosis of mendelian disorders. N Engl J Med 2013;369:1502-11.

62. Jacob HJ, Abrams K, Bick DP, Brodie K, Dimmock DP, Farrell M, et al. Genomics in clinical practice: lessons from the front lines. Sci Transl Med 2013;5:194cm5.

63. Jones MA, Rhodenizer D, da Silva C, Huff IJ, Keong L, Bean LJ, et al. Molecular diagnostic testing for congenital disorders of glycosylation $(C D G)$ : detection rate for single gene testing and next generation sequencing panel testing. Mol Genet Metab 2013;110:78-85.

64. Vincent LM, Dugan EK, Funari T, Richard G, Meck J. 78: Multi-gene NGS panel yields high diagnostic rate of skeletal dysplasias detected by fetal ultrasound. Am J Obstet Gynecol 2018;218:S57-S8.

65. Takahashi JS, Pinto LH, Vitaterna MH. Forward and reverse genetic approaches to behavior in the mouse. Science 1994;264:1724-33.

66. Schulze TG and McMahon FJ. Defining the phenotype in human genetic studies: forward genetics and reverse phenotyping. Hum Hered 2004:58:131-8

67. Boycott KM, Vanstone MR, Bulman DE, MacKenzie AE. Rare-disease genetics in the era of next-generation sequencing: discovery to translation. Nat Rev Genet 2013;14:681-91.

68. Arif B, Kumar KR, Seibler P, Vulinovic F, Fatima A, Winkler S, et al. A novel OPA3 mutation revealed by exome sequencing: an example of reverse phenotyping. JAMA Neurol 2013;70:783-7.

69. Urreizti R, Cueto-Gonzalez AM, Franco-Valls H, Mort-Farre S, RocaAyats $\mathrm{N}$, Ponomarenko J, et al. A de novo nonsense mutation in MAGEL2 in a patient initially diagnosed as Opitz-C: similarities between Schaaf-Yang and Opitz-C syndromes. Sci Rep 2017;7:44138.

70. Graziano C, Wischmeijer A, Pippucci T, Fusco C, Diquigiovanni C, Noukas M, et al. Syndromic intellectual disability: a new phenotype caused by an aromatic amino acid decarboxylase gene (DDC) variant. Gene 2015:559:144-8.

71. Liu H, Sawyer SL, Gos M, Grynspan D, Issa K, Ramphal R, et al. Atypi- 
cal fibrodysplasia ossificans progressiva diagnosed by whole-exome sequencing. Am J Med Genet A 2015;167:1337-41.

72. Worthey EA, Mayer AN, Syverson GD, Helbling D, Bonacci BB, Decker $B$, et al. Making a definitive diagnosis: successful clinical application of whole exome sequencing in a child with intractable inflammatory bowel disease. Genet Med 2011;13:255-62.

73. Dillon OJ, Lunke S, Stark Z, Yeung A, Thorne N, Melbourne Genomics Health Alliance, et al. Exome sequencing has higher diagnostic yield compared to simulated disease-specific panels in children with suspected monogenic disorders. Eur J Hum Genet 2018;26:644-51.

74. Consugar MB, Navarro-Gomez D, Place EM, Bujakowska KM, Sousa ME, Fonseca-Kelly ZD, et al. Panel-based genetic diagnostic testing for inherited eye diseases is highly accurate and reproducible, and more sensitive for variant detection, than exome sequencing. Genet Med 2015;17:253-61.

75. Guan Q, Balciuniene J, Cao K, Fan Z, Biswas S, Wilkens A, et al. AUDIOME: a tiered exome sequencing-based comprehensive gene panel for the diagnosis of heterogeneous nonsyndromic sensorineural hearing loss. Genet Med 2018;20:1600-8.

76. Shashi V, McConkie-Rosell A, Rosell B, Schoch K, Vellore K, McDonald $M$, et al. The utility of the traditional medical genetics diagnostic evaluation in the context of next-generation sequencing for undiagnosed genetic disorders. Genet Med 2014;16:176-82.

77. Kalia SS, Adelman K, Bale SJ, Chung WK, Eng C, Evans JP, et al. Recommendations for reporting of secondary findings in clinical exome and genome sequencing, 2016 update (ACMG SF v2.0): a policy statement of the American College of Medical Genetics and Genomics. Genet Med 2017;19:249-55.

78. Retterer K, Juusola J, Cho MT, Vitazka P, Millan F, Gibellini F, et al. Clinical application of whole-exome sequencing across clinical indications. Genet Med 2016;18:696-704.

79. Tan TY, Dillon OJ, Stark Z, Schofield D, Alam K, Shrestha R, et al. Diagnostic impact and cost-effectiveness of whole-exome sequencing for ambulant children with suspected monogenic conditions. JAMA Pediatr 2017;171:855-62.

80. Yang Y, Muzny DM, Xia F, Niu Z, Person R, Ding Y, et al. Molecular findings among patients referred for clinical whole-exome sequencing. JAMA 2014;312:1870-9.

81. Farwell KD, Shahmirzadi L, El-Khechen D, Powis Z, Chao EC, Tippin Davis B, et al. Enhanced utility of family-centered diagnostic exome sequencing with inheritance model-based analysis: results from 500 unselected families with undiagnosed genetic conditions. Genet Med 2015; 17:578-86.

82. Xiao B, Qiu W, Ji X, Liu X, Huang Z, Liu H, et al. Marked yield of reevaluating phenotype and exome/target sequencing data in 33 individuals with intellectual disabilities. Am J Med Genet A 2018;176:107-15.

83. Belkadi A, Bolze A, Itan Y, Cobat A, Vincent QB, Antipenko A, et al. Whole-genome sequencing is more powerful than whole-exome sequencing for detecting exome variants. Proc Natl Acad Sci U S A 2015;112:5473-8.

84. Stavropoulos DJ, Merico D, Jobling R, Bowdin S, Monfared N, Thiruvahindrapuram $\mathrm{B}$, et al. Whole genome sequencing expands diagnostic utility and improves clinical management in pediatric medicine. NPJ Genom Med 2016;1:15012.

85. Ellingford JM, Barton S, Bhaskar S, Williams SG, Sergouniotis PI, O'Sullivan J, et al. Whole genome sequencing increases molecular diagnostic yield compared with current diagnostic testing for inherited retinal disease. Ophthalmology 2016;123:1143-50.

86. Farnaes L, Hildreth A, Sweeney NM, Clark MM, Chowdhury S, Nahas S, et al. Rapid whole-genome sequencing decreases infant morbidity and cost of hospitalization. NPJ Genom Med 2018;3:10

87. Petrikin JE, Willig LK, Smith LD, Kingsmore SF. Rapid whole genome sequencing and precision neonatology. Semin Perinatol 2015;39:62331.

88. Schwarze K, Buchanan J, Taylor JC, Wordsworth S. Are whole-exome and whole-genome sequencing approaches cost-effective? A systematic review of the literature. Genet Med 2018;20:1122-30.

89. Ghemlas I, Li H, Zlateska B, Klaassen R, Fernandez CV, Yanofsky RA, et al. Improving diagnostic precision, care and syndrome definitions using comprehensive next-generation sequencing for the inherited bone marrow failure syndromes. J Med Genet 2015;52:575-84.

90. Meng L, Pammi M, Saronwala A, Magoulas P, Ghazi AR, Vetrini F, et al. Use of exome sequencing for infants in intensive care units: ascertainment of severe single-gene disorders and effect on medical management. JAMA Pediatr 2017;171:e173438.

91. Surrey LF, MacFarland SP, Chang F, Cao K, Rathi KS, Akgumus GT, et al. Clinical utility of custom-designed NGS panel testing in pediatric tumors. Genome Med 2019;11:32.

92. Miller TE, Yang M, Bajor D, Friedman JD, Chang RYC, Dowlati A, et al. Clinical utility of reflex testing using focused next-generation sequencing for management of patients with advanced lung adenocarcinoma. J Clin Pathol 2018;71:1108-15.

93. Kim H, Yun JW, Lee ST, Kim HJ, Kim SH, Kim JW, et al. Korean society for genetic diagnostics guidelines for validation of next-generation sequencing-based somatic variant detection in hematologic malignancies. Ann Lab Med 2019;39:515-23.

94. Chang F, Lin F, Cao K, Surrey LF, Aplenc R, Bagatell R, et al. Development and clinical validation of a large fusion gene panel for pediatric cancers. J Mol Diagn 2019;21:873-83.

95. Hutchins RJ, Phan KL, Saboor A, Miller JD, Muehlenbachs A, CDC NGS Quality Workgroup. Practical guidance to implementing quality management systems in public health laboratories performing nextgeneration sequencing: personnel, equipment, and process management (Phase 1). J Clin Microbiol 2019;57:e00261-19.

96. Jennings LJ, Arcila ME, Corless C, Kamel-Reid S, Lubin IM, Pfeifer J, et al. Guidelines for validation of next-generation sequencing-based oncology panels: a joint consensus recommendation of the Association for Molecular Pathology and College of American Pathologists. J Mol Diagn 2017;19:341-65.

97. Li MM, Datto M, Duncavage EJ, Kulkarni S, Lindeman NI, Roy S, et al. Standards and guidelines for the interpretation and reporting of sequence variants in cancer: a joint consensus recommendation of the Association for Molecular Pathology, American Society of Clinical Oncology, and College of American Pathologists. J Mol Diagn 2017;19:423.

98. Roy S, Coldren C, Karunamurthy A, Kip NS, Klee EW, Lincoln SE, et al. Standards and guidelines for validating next-generation sequencing bioinformatics pipelines: a joint recommendation of the Association for Molecular Pathology and the College of American Pathologists. J Mol Diagn 2018;20:4-27.

99. Luthra R, Patel KP, Routbort MJ, Broaddus RR, Yau J, Simien C, et al. A targeted high-throughput next-generation sequencing panel for clinical screening of mutations, gene amplifications, and fusions in solid tumors. J Mol Diagn 2017; 19:255-64.

100. Sakai K, Ohira T, Matsubayashi J, Yoneshige A, Ito A, Mitsudomi T, et al. Performance of Oncomine Fusion Transcript kit for formalin-fixed, paraffin-embedded lung cancer specimens. Cancer Sci 2019;110: 2044-9.

101. Zehir A, Benayed R, Shah RH, Syed A, Middha S, Kim HR, et al. Mutational landscape of metastatic cancer revealed from prospective clini- 
cal sequencing of 10,000 patients. Nat Med 2017;23:703-13.

102. Frampton GM, Fichtenholtz A, Otto GA, Wang K, Downing SR, He J, et al. Development and validation of a clinical cancer genomic profiling test based on massively parallel DNA sequencing. Nat Biotechnol 2013;31:1023-31.

103. Cheng DT, Mitchell TN, Zehir A, Shah RH, Benayed R, Syed A, et al. Memorial Sloan Kettering-integrated mutation profiling of actionable cancer targets (MSK-IMPACT): a hybridization capture-based nextgeneration sequencing clinical assay for solid tumor molecular oncology. J Mol Diagn 2015;17:251-64.

104. Hodgson DR, Dougherty BA, Lai Z, Fielding A, Grinsted L, Spencer S, et al. Candidate biomarkers of PARP inhibitor sensitivity in ovarian cancer beyond the BRCA genes. Br J Cancer 2018;119:1401-9.

105. Coccaro N, Anelli L, Zagaria A, Specchia G, Albano F. Next-generation sequencing in acute lymphoblastic leukemia. Int J Mol Sci 2019;20: 2929.

106. Papaemmanuil E, Gerstung M, Bullinger L, Gaidzik VI, Paschka P, Roberts ND, et al. Genomic classification and prognosis in acute myeloid leukemia. N Engl J Med 2016;374:2209-21.

107. Dufour A, Schneider F, Metzeler KH, Hoster E, Schneider S, Zellmeier E, et al. Acute myeloid leukemia with biallelic CEBPA gene mutations and normal karyotype represents a distinct genetic entity associated with a favorable clinical outcome. J Clin Oncol 2010;28:570-7.

108. Sood R, Kamikubo Y, Liu P. Role of RUNX1 in hematological malignancies. Blood 2017;129:2070-82.

109. Daver N, Schlenk RF, Russell NH, Levis MJ. Targeting FLT3 mutations in AML: review of current knowledge and evidence. Leukemia 2019; 33:299-312.

110. Medeiros BC, Fathi AT, DiNardo CD, Pollyea DA, Chan SM, Swords R. Isocitrate dehydrogenase mutations in myeloid malignancies. Leukemia 2017;31:272-81.

111. Ley TJ, Ding L, Walter MJ, McLellan MD, Lamprecht T, Larson DE, et al. DNMT3A mutations in acute myeloid leukemia. N Engl J Med 2010;363:2424-33.

112. Delhommeau F, Dupont S, Della Valle V, James C, Trannoy S, Masse A, et al. Mutation in TET2 in myeloid cancers. N Engl J Med 2009;360: 2289-301.

113. Weissmann S, Alpermann T, Grossmann V, Kowarsch A, Nadarajah N, Eder C, et al. Landscape of TET2 mutations in acute myeloid leukemia. Leukemia 2012;26:934-42.

114. Chou WC, Chou SC, Liu CY, Chen CY, Hou HA, Kuo YY, et al. TET2 mutation is an unfavorable prognostic factor in acute myeloid leukemia patients with intermediate-risk cytogenetics. Blood 2011;118:3803-10.

115. Itzykson R, Kosmider O, Cluzeau T, Mansat-De Mas V, Dreyfus F, Beyne-Rauzy $\mathrm{O}$, et al. Impact of TET2 mutations on response rate to azacitidine in myelodysplastic syndromes and low blast count acute myeloid leukemias. Leukemia 2011;25:1147-52.

116. Metzeler KH, Herold T, Rothenberg-Thurley M, Amler S, Sauerland MC, Gorlich D, et al. Spectrum and prognostic relevance of driver gene mutations in acute myeloid leukemia. Blood 2016;128:686-98.

117. Campo E, Harris NL, Pileri SA, Jaffe ES, Stein H, Thiele J. WHO Classification of Tumours of Haematopoietic and Lymphoid Tissues. Lyon, France: IARC;2017.

118. Rosell R, Moran T, Queralt C, Porta R, Cardenal F, Camps C, et al. Screening for epidermal growth factor receptor mutations in lung cancer. N Engl J Med 2009;361:958-67.

119. Cancer Genome Atlas Research Network. Comprehensive molecular profiling of lung adenocarcinoma. Nature 2014;511:543-50.

120. D'Angelo SP, Pietanza MC, Johnson ML, Riely GJ, Miller VA, Sima CS, et al. Incidence of EGFR exon 19 deletions and L858R in tumor speci- mens from men and cigarette smokers with lung adenocarcinomas. J Clin Oncol 2011;29:2066-70.

121. Shaw AT and Engelman JA. ALK in lung cancer: past, present, and future. J Clin Oncol 2013;31:1105-11.

122. Shaw AT, Ou SH, Bang YJ, Camidge DR, Solomon BJ, Salgia R, et al. Crizotinib in ROS1-rearranged non-small-cell lung cancer. N Engl J Med 2014;371:1963-71.

123. Shaw AT, Riely GJ, Bang YJ, Kim DW, Camidge DR, Solomon BJ, et al. Crizotinib in ROS1-rearranged advanced non-small-cell lung cancer (NSCLC): updated results, including overall survival, from PROFILE 1001. Ann Oncol 2019;30:1121-6.

124. Lindeman NI, Cagle PT, Aisner DL, Arcila ME, Beasley MB, Bernicker $\mathrm{EH}$, et al. Updated molecular testing guideline for the selection of lung cancer patients for treatment with targeted tyrosine kinase inhibitors: guideline from the College of American Pathologists, the International Association for the Study of Lung Cancer, and the Association for Molecular Pathology. Arch Pathol Lab Med 2018;142:p321-46.

125. Yamamoto $\mathrm{H}$ and Imai K. An updated review of microsatellite instability in the era of next-generation sequencing and precision medicine. Semin Oncol 2019;46:261-70.

126. Zhao P, Li L, Jiang X, Li Q. Mismatch repair deficiency/microsatellite instability-high as a predictor for anti-PD-1/PD-L1 immunotherapy efficacy. J Hematol Oncol 2019;12:54.

127. Marcus L, Lemery SJ, Keegan P, Pazdur R. FDA approval summary: pembrolizumab for the treatment of microsatellite instability-high solid tumors. Clin Cancer Res 2019;25:3753-8.

128. Mehrvarz Sarshekeh A, Overman MJ, Kopetz S. Nivolumab in the treatment of microsatellite instability high metastatic colorectal cancer. Future Oncol 2018;14:1869-74.

129. Overman MJ, Lonardi S, Wong KYM, Lenz HJ, Gelsomino F, Aglietta M, et al. Durable clinical benefit with nivolumab plus ipilimumab in DNA mismatch repair-deficient/microsatellite instability-high metastatic colorectal cancer. J Clin Oncol 2018;36:773-9.

130. Cocco E, Scaltriti M, Drilon A. NTRK fusion-positive cancers and TRK inhibitor therapy. Nat Rev Clin Oncol 2018;15:731-47.

131. Hsiao SJ, Zehir A, Sireci AN, Aisner DL. Detection of tumor NTRK gene fusions to identify patients who may benefit from tyrosine kinase (TRK) inhibitor therapy. J Mol Diagn 2019;21:553-71.

132. Ricciuti B, Genova C, Crino L, Libra M, Leonardi GC. Antitumor activity of larotrectinib in tumors harboring NTRK gene fusions: a short review on the current evidence. Onco Targets Ther 2019;12:3171-9.

133. Drilon A, Laetsch TW, Kummar S, DuBois SG, Lassen UN, Demetri $\mathrm{GD}$, et al. Efficacy of larotrectinib in TRK fusion-positive cancers in adults and children. N Engl J Med 2018;378:731-9.

134. Doebele RC, Drilon A, Paz-Ares L, Siena S, Shaw AT, Farago AF, et al. Entrectinib in patients with advanced or metastatic NTRK fusion-positive solid tumours: integrated analysis of three phase 1-2 trials. Lancet Oncol 2020;21:271-82.

135. Drilon A, Siena S, Dziadziuszko R, Barlesi F, Krebs MG, Shaw AT, et al. Entrectinib in ROS1 fusion-positive non-small-cell lung cancer: integrated analysis of three phase 1-2 trials. Lancet Oncol 2020;21:261-70.

136. Chan TA, Yarchoan M, Jaffee E, Swanton C, Quezada SA, Stenzinger A, et al. Development of tumor mutation burden as an immunotherapy biomarker: utility for the oncology clinic. Ann Oncol 2019;30:44-56.

137. Steuer CE, Ramalingam SS. Tumor mutation burden: leading immunotherapy to the era of precision medicine? J Clin Oncol 2018;36:631-2.

138. Cunanan KM, lasonos A, Shen R, Begg CB, Gonen M. An efficient basket trial design. Stat Med 2017;36:1568-79.

139. Strzebonska K and Waligora M. Umbrella and basket trials in oncology: ethical challenges. BMC Med Ethics 2019;20:58. 
140. McNeil C. NCl-MATCH launch highlights new trial design in precisionmedicine era. J Natl Cancer Inst 2015;107:djv193.

141. Luskin MR, Murakami MA, Manalis SR, Weinstock DM. Targeting minimal residual disease: a path to cure? Nat Rev Cancer 2018;18:255-63.

142. Cilloni D, Petiti J, Rosso V, Andreani G, Dragani M, Fava C, et al. Digital PCR in myeloid malignancies: ready to replace quantitative PCR? Int J Mol Sci 2019;20:2249.

143. Romano A, Palumbo GA, Parrinello NL, Conticello C, Martello M, Terragna $\mathrm{C}$. Minimal residual disease assessment within the bone marrow of multiple myeloma: a review of caveats, clinical significance and future perspectives. Front Oncol 2019;9:699.

144. Wu D, Emerson RO, Sherwood A, Loh ML, Angiolillo A, Howie B, et al. Detection of minimal residual disease in $\mathrm{B}$ lymphoblastic leukemia by high-throughput sequencing of IGH. Clin Cancer Res 2014;20:4540-8.

145. Wood B, Wu D, Crossley B, Dai Y, Williamson D, Gawad C, et al. Measurable residual disease detection by high-throughput sequencing improves risk stratification for pediatric B-ALL. Blood 2018;131:1350-9.

146. Berger MF and Mardis ER The emerging clinical relevance of genomics in cancer medicine. Nat Rev Clin Oncol 2018;15:353-65.

147. Chin RI, Chen K, Usmani A, Chua C, Harris PK, Binkley MS, et al. Detection of solid tumor molecular residual disease (MRD) using circulating tumor DNA (ctDNA). Mol Diagn Ther 2019;23:311-31.

148. Rossi $\mathrm{G}$ and Ignatiadis M. Promises and pitfalls of using liquid biopsy for precision medicine. Cancer Res 2019;79:2798-804.

149. Heitzer E, Haque IS, Roberts CES, Speicher MR. Current and future perspectives of liquid biopsies in genomics-driven oncology. Nat Rev Genet 2019;20:71-88.

150. Ulrich BC and Paweletz CP. Cell-Free DNA in oncology: gearing up for clinic. Ann Lab Med 2018;38:1-8.

151. Brown P. The Cobas EGFR Mutation Test v2 assay. Future Oncol 2016; 12:451-2.

152. Clark TA, Chung JH, Kennedy M, Hughes JD, Chennagiri N, Lieber DS, et al. Analytical validation of a hybrid capture-based next-generation sequencing clinical assay for genomic profiling of cell-free circulating tumor DNA. J Mol Diagn 2018;20:686-702.

153. Aravanis AM, Lee M, Klausner RD. Next-generation sequencing of circulating tumor DNA for early cancer detection. Cell 2017;168:571-4.

154. Wang Y, Li L, Douville C, Cohen JD, Yen TT, Kinde I, et al. Evaluation of liquid from the Papanicolaou test and other liquid biopsies for the detection of endometrial and ovarian cancers. Sci Transl Med 2018;10: eaap8793.

155. Cohen JD, Li L, Wang Y, Thoburn C, Afsari B, Danilova L, et al. Detection and localization of surgically resectable cancers with a multi-analyte blood test. Science 2018;359:926-30.

156. Merker JD, Oxnard GR, Compton C, Diehn M, Hurley P, Lazar AJ, et al. Circulating tumor DNA analysis in patients with cancer: American Society of Clinical Oncology and College of American Pathologists joint review. J Clin Oncol 2018;36:1631-41.

157. Razavi P, Li BT, Brown DN, Jung B, Hubbell E, Shen R, et al. High-intensity sequencing reveals the sources of plasma circulating cell-free DNA variants. Nat Med 2019;25:1928-37.

158. Lozano R, Naghavi M, Foreman K, Lim S, Shibuya K, Aboyans V, et al. Global and regional mortality from 235 causes of death for 20 age groups in 1990 and 2010: a systematic analysis for the Global Burden of Disease Study 2010. Lancet 2012;380:2095-128.

159. Ewig S, Torres A, Angeles Marcos M, Angrill J, Rano A, de Roux A, et al. Factors associated with unknown aetiology in patients with community-acquired pneumonia. Eur Respir J 2002;20:1254-62.

160. Bleeker-Rovers CP, Vos FJ, de Kleijn EM, Mudde AH, Dofferhoff TS, Richter $\mathrm{C}$, et al. A prospective multicenter study on fever of unknown origin: the yield of a structured diagnostic protocol. Medicine (Baltimore) 2007;86:26-38.

161. Karkhane M, Pourhosiengholi MA, Akbariyan Torkabad MR, Kimiia Z, Mortazavi SM, Hossieni Aghdam SK, et al. Annual antibiotic related economic burden of healthcare associated infections; a cross-sectional population based study. Iran J Pharm Res 2016;15:605-10.

162. Weng QY, Raff AB, Cohen JM, Gunasekera N, Okhovat JP, Vedak P, et al. Costs and consequences associated with misdiagnosed lower extremity cellulitis. JAMA Dermatol 2017;153:141-6.

163. Amexo M, Tolhurst R, Barnish G, Bates I. Malaria misdiagnosis: effects on the poor and vulnerable. Lancet 2004;364:1896-8.

164. Kapur V, Li LL, Hamrick MR, Plikaytis BB, Shinnick TM, Telenti A, et al. Rapid Mycobacterium species assignment and unambiguous identification of mutations associated with antimicrobial resistance in Mycobacterium tuberculosis by automated DNA sequencing. Arch Pathol Lab Med 1995;119:131-8.

165. Tang YW, Ellis NM, Hopkins MK, Smith DH, Dodge DE, Persing DH. Comparison of phenotypic and genotypic techniques for identification of unusual aerobic pathogenic gram-negative bacilli. J Clin Microbiol 1998;36:3674-9.

166. Allicock OM, Guo C, Uhlemann AC, Whittier S, Chauhan LV, Garcia J, et al. BacCapSeq: a platform for diagnosis and characterization of bacterial infections. mBio 2018;9:e02007-18.

167. Briese T, Kapoor A, Mishra N, Jain K, Kumar A, Jabado OJ, et al. Virome capture sequencing enables sensitive viral diagnosis and comprehensive virome analysis. mBio 2015;6:e01491-15.

168. Buss SN, Leber A, Chapin K, Fey PD, Bankowski MJ, Jones MK, et al. Multicenter evaluation of the BioFire FilmArray gastrointestinal panel for etiologic diagnosis of infectious gastroenteritis. J Clin Microbiol 2015; 53:915-25.

169. Babady NE. The FilmArray® respiratory panel: an automated, broadly multiplexed molecular test for the rapid and accurate detection of respiratory pathogens. Expert Rev Mol Diagn 2013;13:779-88.

170. Leber AL, Everhart K, Balada-Llasat JM, Cullison J, Daly J, Holt S, et al. Multicenter evaluation of biofire filmarray meningitis/encephalitis pane for detection of bacteria, viruses, and yeast in cerebrospinal fluid specimens. J Clin Microbiol 2016;54:2251-61.

171. CRyPTIC Consortium and the 100,000 Genomes Project, Allix-Beguec C, Arandjelovic I, Bi L, Beckert P, Bonnet M, et al. Prediction of susceptibility to first-line tuberculosis drugs by DNA sequencing. N Engl J Med 2018;379:1403-15.

172. Nimmo C, Doyle R, Burgess C, Williams R, Gorton R, McHugh TD, et al. Rapid identification of a Mycobacterium tuberculosis full genetic drug resistance profile through whole genome sequencing directly from sputum. Int J Infect Dis 2017;62:44-6.

173. Quan TP, Bawa Z, Foster D, Walker T, Del Ojo Elias C, Rathod P, et al. Evaluation of whole-genome sequencing for mycobacterial species identification and drug susceptibility testing in a clinical setting: a largescale prospective assessment of performance against line probe assays and phenotyping. J Clin Microbiol 2018;56:e01480-17.

174. Ellington MJ, Ekelund O, Aarestrup FM, Canton R, Doumith M, Giske C, et al. The role of whole genome sequencing in antimicrobial susceptibility testing of bacteria: report from the EUCAST Subcommittee. Clin Microbiol Infect 2017;23:2-22.

175. Burnham P, Dadhania D, Heyang M, Chen F, Westblade LF, Suthanthiran $\mathrm{M}$, et al. Urinary cell-free DNA is a versatile analyte for monitoring infections of the urinary tract. Nat Commun 2018;9:2412.

176. Doan T, Acharya NR, Pinsky BA, Sahoo MK, Chow ED, Banaei N, et al. Metagenomic DNA sequencing for the diagnosis of intraocular infections. Ophthalmology 2017;124:1247-8. 
177. Graf EH, Simmon KE, Tardif KD, Hymas W, Flygare S, Eilbeck K, et al. Unbiased detection of respiratory viruses by use of RNA sequencingbased metagenomics: a systematic comparison to a commercial PCR panel. J Clin Microbiol 2016;54:1000-7.

178. Mongkolrattanothai K, Naccache SN, Bender JM, Samayoa E, Pham E, Yu G, et al. Neurobrucellosis: unexpected answer from metagenomic next-generation sequencing. J Pediatric Infect Dis Soc 2017;6:393-8.

179. Simner PJ, Miller HB, Breitwieser FP, Pinilla Monsalve G, Pardo CA, Salzberg SL, et al. Development and optimization of metagenomic next-generation sequencing methods for cerebrospinal fluid diagnostics. J Clin Microbiol 2018;56:e00472-18.

180. Schlaberg R, Chiu CY, Miller S, Procop GW, Weinstock G, Professional Practice Committee and Committee on Laboratory Practices of the American Society for Microbiology, et al. Validation of metagenomic next-generation sequencing tests for universal pathogen detection. Arch Pathol Lab Med 2017;141:776-86.

181. Miller S, Naccache SN, Samayoa E, Messacar K, Arevalo S, Federman $\mathrm{S}$, et al. Laboratory validation of a clinical metagenomic sequencing assay for pathogen detection in cerebrospinal fluid. Genome Res 2019; 29:831-42.

182. Hasan MR, Rawat A, Tang P, Jithesh PV, Thomas E, Tan R, et al. Depletion of human DNA in spiked clinical specimens for improvement of sensitivity of pathogen detection by next-generation sequencing. J Clin Microbiol 2016;54:919-27.

183. Blauwkamp TA, Thair S, Rosen MJ, Blair L, Lindner MS, Vilfan ID, et al. Analytical and clinical validation of a microbial cell-free DNA sequencing test for infectious disease. Nat Microbiol 2019;4:663-74.

184. Thoendel M, Jeraldo P, Greenwood-Quaintance KE, Yao J, Chia N, Hanssen AD, et al. Impact of contaminating DNA in whole-genome amplification kits used for metagenomic shotgun sequencing for infection diagnosis. J Clin Microbiol 2017;55:1789-801.

185. Naccache SN, Greninger AL, Lee D, Coffey LL, Phan T, Rein-Weston A, et al. The perils of pathogen discovery: origin of a novel parvovirus-like hybrid genome traced to nucleic acid extraction spin columns. J Virol 2013;87:11966-77.

186. de Goffau MC, Lager S, Salter SJ, Wagner J, Kronbichler A, CharnockJones DS, et al. Recognizing the reagent microbiome. Nat Microbiol 2018;3:851-3

187. Quick J, Loman NJ, Duraffour S, Simpson JT, Severi E, Cowley L, et al. Real-time, portable genome sequencing for Ebola surveillance. Nature 2016;530:228-32.

188. Zhou P, Yang XL, Wang XG, Hu B, Zhang L, Zhang W, et al. A pneumonia outbreak associated with a new coronavirus of probable bat origin. Nature 2020;579:270-3.

189. Sammons JS, Graf EH, Townsend S, Hoegg CL, Smathers SA, Coffin SE, et al. Outbreak of adenovirus in a neonatal intensive care unit: critical importance of equipment cleaning during inpatient ophthalmologic examinations. Ophthalmology 2019;126:137-43.

190. Etienne KA, Roe CC, Smith RM, Vallabhaneni S, Duarte C, Escadon P, et al. Whole-genome sequencing to determine origin of multinational outbreak of Sarocladium kiliense bloodstream infections. Emerg Infect Dis 2016;22:476-81.

191. Snitkin ES, Zelazny AM, Thomas PJ, Stock F, Group NCSP, Henderson DK, et al. Tracking a hospital outbreak of carbapenem-resistant Klebsiella pneumoniae with whole-genome sequencing. Sci Transl Med 2012;4:148ra116

192. Paterson GK, Harrison EM, Murray GGR, Welch JJ, Warland JH, Holden MTG, et al. Capturing the cloud of diversity reveals complexity and heterogeneity of MRSA carriage, infection and transmission. Nat Commun 2015;6:6560.
193. Lockhart SR, Etienne KA, Vallabhaneni S, Farooqi J, Chowdhary A, Govender NP, et al. Simultaneous emergence of multidrug-resistant Candida auris on 3 continents confirmed by whole-genome sequencing and epidemiological analyses. Clin Infect Dis 2017;64:134-40.

194. Hoffmann M, Luo Y, Monday SR, Gonzalez-Escalona N, Ottesen AR, Muruvanda $T$, et al. Tracing origins of the Salmonella Bareilly strain causing a food-borne outbreak in the United States. J Infect Dis 2016; 213:502-8.

195. Jackson BR, Tarr C, Strain E, Jackson KA, Conrad A, Carleton H, et al. Implementation of nationwide real-time whole-genome sequencing to enhance listeriosis outbreak detection and investigation. Clin Infect Dis 2016;63:380-6.

196. Moura A, Tourdjman M, Leclercq A, Hamelin E, Laurent E, Fredriksen $\mathrm{N}$, et al. Real-time whole-genome sequencing for surveillance of Listeria monocytogenes, France. Emerg Infect Dis 2017;23:1462-70.

197. Shepard SS, Meno S, Bahl J, Wilson MM, Barnes J, Neuhaus E. Viral deep sequencing needs an adaptive approach: IRMA, the iterative refinement meta-assembler. BMC Genomics 2016;17:708.

198. Gwinn M, MacCannell DR, Khabbaz RF. Integrating advanced molecular technologies into public health. J Clin Microbiol 2017;55:703-14.

199. Thoendel MJ, Jeraldo PR, Greenwood-Quaintance KE, Yao JZ, Chia N, Hanssen AD, et al. Identification of prosthetic joint infection pathogens using a shotgun metagenomics approach. Clin Infect Dis 2018;67: 1333-8.

200. Ivy MI, Thoendel MJ, Jeraldo PR, Greenwood-Quaintance KE, Hanssen $A D$, Abdel MP, et al. Direct detection and identification of prosthetic joint infection pathogens in synovial fluid by metagenomic shotgun sequencing. J Clin Microbiol 2018;56:e00402-18.

201. Zhou Y, Wylie KM, El Feghaly RE, Mihindukulasuriya KA, Elward A, Haslam DB, et al. Metagenomic approach for identification of the pathogens associated with diarrhea in stool specimens. J Clin Microbiol 2016;54:368-75

202. Li Z, Breitwieser FP, Lu J, Jun AS, Asnaghi L, Salzberg SL, et al. Identifying corneal infections in formalin-fixed specimens using next generation sequencing. Invest Ophthalmol Vis Sci 2018;59:280-8.

203. Wilson MR, O'Donovan BD, Gelfand JM, Sample HA, Chow FC, Betjemann JP, et al. Chronic meningitis investigated via metagenomic nextgeneration sequencing. JAMA Neurol 2018;75:947-55.

204. Grumaz S, Stevens P, Grumaz C, Decker SO, Weigand MA, Hofer S, et al. Next-generation sequencing diagnostics of bacteremia in septic patients. Genome Med 2016;8:73.

205. Long Y, Zhang Y, Gong Y, Sun R, Su L, Lin X, et al. Diagnosis of sepsis with ell-free DNA by next-generation sequencing technology in ICU patients. Arch Med Res 2016;47:365-71.

206. Wylie KM, Mihindukulasuriya KA, Sodergren E, Weinstock GM, Storch GA. Sequence analysis of the human virome in febrile and afebrile children. PLoS One 2012;7:e27735.

207. Wilson MR, Naccache SN, Samayoa E, Biagtan M, Bashir H, Yu G, et al. Actionable diagnosis of neuroleptospirosis by next-generation sequencing. N Engl J Med 2014;370:2408-17.

208. Hoffmann B, Tappe D, Hoper D, Herden C, Boldt A, Mawrin C, et al. A variegated squirrel bornavirus associated with fatal human encephalitis. N Engl J Med 2015;373:154-62.

209. Greninger AL, Messacar K, Dunnebacke T, Naccache SN, Federman S, Bouquet J, et al. Clinical metagenomic identification of Balamuthia mandrillaris encephalitis and assembly of the draft genome: the continuing case for reference genome sequencing. Genome Med 2015; 7:113.

210. Wilson MR, Shanbhag NM, Reid MJ, Singhal NS, Gelfand JM, Sample $\mathrm{HA}$, et al. Diagnosing Balamuthia mandrillaris encephalitis with 
metagenomic deep sequencing. Ann Neurol 2015;78:722-30.

211. Schmidt K, Mwaigwisya S, Crossman LC, Doumith M, Munroe D, Pires $\mathrm{C}$, et al. Identification of bacterial pathogens and antimicrobial resistance directly from clinical urines by nanopore-based metagenomic sequencing. J Antimicrob Chemother 2017;72:104-14.

212. Lemon JK, Khil PP, Frank KM, Dekker JP. Rapid nanopore sequencing of plasmids and resistance gene detection in clinical isolates. J Clin Microbiol 2017;55:3530-43.

213. Tamma PD, Fan Y, Bergman Y, Pertea G, Kazmi AQ, Lewis S, et al. Applying rapid whole-genome sequencing to predict phenotypic antimicrobial susceptibility testing results among carbapenem-resistant Klebsiella pneumoniae clinical isolates. Antimicrob Agents Chemother 2019;63:e01923-18.

214. Tzou PL, Ariyaratne P, Varghese V, Lee C, Rakhmanaliev E, Villy C, et al. Comparison of an in vitro diagnostic next-generation sequencing assay with Sanger sequencing for HIV-1 genotypic resistance testing. J Clin Microbiol 2018;56:e00105-18.

215. Tyson GH, McDermott PF, Li C, Chen Y, Tadesse DA, Mukherjee S, et al. WGS accurately predicts antimicrobial resistance in Escherichia coli. J Antimicrob Chemother 2015;70:2763-9.

216. Shea J, Halse TA, Lapierre P, Shudt M, Kohlerschmidt D, Van Roey P, et al. Comprehensive whole-genome sequencing and reporting of drug resistance profiles on clinical cases of Mycobacterium tuberculosis in New York State. J Clin Microbiol 2017;55:1871-82.

217. Jaillard M, van Belkum A, Cady KC, Creely D, Shortridge D, Blanc B, et al. Correlation between phenotypic antibiotic susceptibility and the resistome in Pseudomonas aeruginosa. Int J Antimicrob Agents 2017; 50:210-8.

218. Sabat AJ, van Zanten E, Akkerboom V, Wisselink G, van Slochteren K, de Boer RF, et al. Targeted next-generation sequencing of the 16S-23S rRNA region for culture-independent bacterial identification - increased discrimination of closely related species. Sci Rep 2017;7:3434.

219. Salipante SJ, Hoogestraat DR, Abbott AN, SenGupta DJ, Cummings LA, Butler-Wu SM, et al. Coinfection of Fusobacterium nucleatum and Actinomyces israelii in mastoiditis diagnosed by next-generation DNA sequencing. J Clin Microbiol 2014;52:1789-92.

220. Sardi SI, Somasekar S, Naccache SN, Bandeira AC, Tauro LB, Campos GS, et al. Coinfections of Zika and chikungunya viruses in Bahia, Brazil, identified by metagenomic next-generation sequencing. J Clin Microbiol 2016;54:2348-53.

221. Miao Q, Ma Y, Wang Q, Pan J, Zhang Y, Jin W, et al. Microbiological di- agnostic performance of metagenomic next-generation sequencing when applied to clinical practice. Clin Infect Dis 2018;67(S2):S231S40.

222. Langelier C, Kalantar KL, Moazed F, Wilson MR, Crawford ED, Deiss T, et al. Integrating host response and unbiased microbe detection for lower respiratory tract infection diagnosis in critically ill adults. Proc Natl Acad Sci U S A 2018;115:E12353-E62.

223. Bal A, Sarkozy C, Josset L, Cheynet V, Oriol G, Becker J, et al. Metagenomic next-generation sequencing reveals individual composition and dynamics of anelloviruses during autologous stem cell transplant recipient management. Viruses 2018;10:633.

224. De Vlaminck I, Khush KK, Strehl C, Kohli B, Luikart H, Neff NF, et al. Temporal response of the human virome to immunosuppression and antiviral therapy. Cell 2013;155:1178-87.

225. De Vlaminck I, Martin L, Kertesz M, Patel K, Kowarsky M, Strehl C, et al. Noninvasive monitoring of infection and rejection after lung transplantation. Proc Natl Acad Sci U S A 2015;112:13336-41.

226. Zhao J, Schloss PD, Kalikin LM, Carmody LA, Foster BK, Petrosino JF, et al. Decade-long bacterial community dynamics in cystic fibrosis airways. Proc Natl Acad Sci U S A 2012;109:5809-14.

227. Morgan XC, Tickle TL, Sokol H, Gevers D, Devaney KL, Ward DV, et al. Dysfunction of the intestinal microbiome in inflammatory bowel disease and treatment. Genome Biol 2012;13:R79.

228. van Nood E, Vrieze A, Nieuwdorp M, Fuentes S, Zoetendal EG, de Vos WM, et al. Duodenal infusion of donor feces for recurrent Clostridium difficile. N Engl J Med 2013;368:407-15.

229. Petersen BS, Fredrich B, Hoeppner MP, Ellinghaus D, Franke A. Opportunities and challenges of whole-genome and -exome sequencing. BMC Genet 2017;18:14.

230. Kim YE, Ki CS, Jang MA. Challenges and considerations in sequence variant interpretation for Mendelian disorders. Ann Lab Med 2019;39: 421-9.

231. Chen G, Ning B, Shi T. Single-cell RNA-seq technologies and related computational data analysis. Front Genet 2019;10:317.

232. Schrader KA, Cheng DT, Joseph V, Prasad M, Walsh M, Zehir A, et al. Germline variants in targeted tumor sequencing using matched normal DNA. JAMA Oncol 2016;2:104-11.

233. Akkari Y, Smith T, Westfall J,Lupo S Implementation of cancer next-generation sequencing testing in a community hospital. Cold Spring Harb Mol Case Stud 2019;5: a003707. 